Revista Brasil. Bot., V.32, n.2, p.213-232, abr.-jun. 2009

\title{
Micrasterias C. Agardh ex Ralfs (Zygnematophyceae) de duas Áreas de Proteção Ambiental da planície litorânea do norte da Bahia, Brasil
}

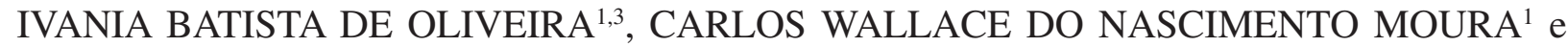 \\ CARLOS EDUARDO DE MATTOS BICUDO ${ }^{2}$
}

(recebido: 14 de fevereiro de 2008; aceito: 22 de janeiro de 2009)

\begin{abstract}
Micrasterias C. Agardh ex Ralfs (Zygnematophyceae) of two Environment Protection Areas of the northern littoral lowland of Bahia, Brazil). Taxonomical survey of genus Micrasterias C. Agardh ex Ralfs of two Environment Protection Areas (APA Rio Capivara and APA Lagoas de Guarajuba), both located in the Camaçari, Bahia State, northeastern Brazil. Ninety-six samples of planktonic and periphytic material studied was collected during the Summer (December 2006 to March 2007) and Winter (May to August 2007), both in lotic and lentic environments. Fourteen taxa were identified, from which $M$. americana (Ehrenb.) Ralfs var. bahiensis I. B. Oliveira, C. E. M. Bicudo \& C. W. N. Moura is described and proposed as new to Science, and 10 constitute pioneer citations for the state of Bahia desmidflora, namely, M. alata G. C. Wall., M. arcuata Bailey var. subpinnatifida West \& G. S. West f. subpinnatifida, M. borgei H. Krieg. var. borgei, M. foliacea Bailey ex Ralfs var. foliacea, M. furcata C. Agardh ex Ralfs var. furcata f. furcata, M. laticeps Nordst. var. laticeps, M. laticeps Nordst. var. acuminata H. Krieg., M. mahabuleshwarensis J. Hobson var. ampullacea (W. M. Maskell) Nordst., M. mahabuleshwarensis J. Hobson var. mahabuleshwarensis f. mahabuleshwarensis, M. pinnatifida (Kütz.) Ralfs var. pinnatifida f. pinnatifida, M. radiosa Ralfs var. elegantior (G. S. West) Croasdale, M. rotata (Grev.) Ralfs var. rotata and M. truncata (Corda) Bréb. ex Ralfs var. pusilla G. S. West. The best represented species in the study area were M. pinnatifida and M. alata, present in $38.6 \%$ and $36.6 \%$ of studied samples, respectively. Micrasterias laticeps var. acuminata and M. americana var. bahiensis, were the least represented ones, since they occurred just in 2,08\% and 1,04\% respectively.
\end{abstract}

Key words - Bahia, Desmidiaceae, floristic survey, Micrasterias

RESUMO - (Micrasterias C. Agardh ex Ralfs (Zygnematophyceae) de duas Áreas de Proteção Ambiental da planície litorânea do norte da Bahia, Brasil). Estudo taxonômico do gênero Micrasterias C. Agardh ex Ralfs realizado em duas Áreas de Proteção Ambiental (APA Rio Capivara e APA Lagoas de Guarajuba), ambas situadas no Município de Camaçari, Estado da Bahia, nordeste do Brasil. Os materiais estudados, de origem do plâncton e do perifíton, provieram de 96 amostras coletadas no verão (dezembro de 2006 a março de 2007) e no inverno (maio a agosto de 2007), em ambientes lóticos e lênticos. Foram identificados 14 táxons, dos quais M. americana (Ehrenb.) Ralfs var. bahiensis I. B. Oliveira, C. E. M. Bicudo \& C. W. N. Moura foi descrita como nova para a ciência e 10 constituem citacões pioneiras para a desmidioflórula da Bahia, quais sejam: M. alata G. C. Wall., M. arcuata Bailey var. subpinnatifida West \& G. S. West f. subpinnatifida, M. borgei H. Krieg. var. borgei, M. foliacea Bailey ex Ralfs var. foliacea, M. furcata C. Agardh ex Ralfs var. furcata f. furcata, M. laticeps Nordst. var. laticeps, M. laticeps Nordst. var. acuminata H. Krieg., M. mahabuleshwarensis J. Hobson var. ampullacea (W. M. Maskell) Nordst., M. mahabuleshwarensis J. Hobson var. mahabuleshwarensis f. mahabuleshwarensis, M. pinnatifida (Kütz.) Ralfs var. pinnatifida f. pinnatifida, M. radiosa Ralfs var. elegantior (G. S. West) Croasdale, M. rotata (Grev.) Ralfs var. rotata e $M$. truncata (Corda) Bréb. ex Ralfs var. pusilla G. S. West. As espécies mais bem representadas na área estudada foram M. alata e M. pinnatifida presentes, respectivamente, em 50\% e 45,83\% das amostras analisadas. Micrasterias laticeps var. acuminata e M. americana var. bahiensis, foram as menos representadas, por terem sido registradas apenas em $2,08 \%$ e $1,04 \%$ respectivamente.

Palavras-chave - Bahia, Desmidiaceae, levantamento florístico, Micrasterias

\section{Introdução}

Existem apenas três trabalhos realizados sobre o levantamento florístico de Desmidiaceae do Estado da

1. Universidade Estadual de Feira de Santana, Programa de PósGraduação em Botânica, Departamento de Ciências Biológicas, Av Universitária, km 3, BR-116, 44031-460 Feira de Santana, Bahia.

2. Instituto de Botânica, Seção de Ecologia, Caixa Postal 3005 , 010611-970 São Paulo, SP, Brasil

3. Autor para correspondência: ivboliveira@gmail.com
Bahia. O primeiro documento sobre a ocorrência do material de Desmidiaceae no Estado da Bahia é o trabalho de Förster (1964). O material estudado proveio de coletas realizadas em 1913, por Paul von Lützelburg nas localidades de Bom Jesus do Rio de Contas (12 ${ }^{\circ} 75^{\prime} \mathrm{S}$,

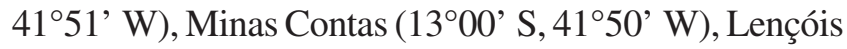
Orange (12 $\left.50^{\circ} \mathrm{S}, 41^{\circ} 00^{\prime} \mathrm{W}\right)$, Serra das Almas ( $15^{\circ} 25^{\prime} \mathrm{S}$, $\left.41^{\circ} 50^{\prime} \mathrm{W}\right)$ e uma localidade não especificada $\left(13^{\circ} 00^{\prime} \mathrm{S}\right.$, $38^{\circ} 00^{\prime}$ W) no Estado da Bahia. Nesse trabalho, aparecem citados 12 gêneros (Actinotaenium, Bambusina, 
Cosmarium, Desmidium, Euastrum, Micrasterias, Pleurotaenium, Phymatodocis, Sphaerozosma, Spondylosium, Staurastrum e Tetmemorus) e o total de 59 táxons infra-específicos. Dentre os gêneros mais bem representados figuram Micrasterias, Cosmarium e Euastrum com 13, 12 e oito espécies, respectivamente.

Martins \& Bicudo (1987) documentaram a ocorrência de 12 gêneros (Actinotaenium, Bambusina, Cosmarium, Desmidium, Euastrum, Ichthyocercus, Micrasterias, Pleurotaenium, Spondylosium, Staurastrum, Staurodesmus e Tetmemorus) e 37 espécies de desmídias identificadas a partir da análise de três amostras coletadas no riacho de Tinharé (Ilha de Tinharé) e de duas outras amostras coletadas na lagoa Grande (Cairu), os dois locais situados no Município de Cairu, Estado da Bahia.

Finalmente, Bicudo \& Martins (1989) descreveram e ilustraram, num estudo realizado sobre as desmídias de três fazendas (Socorro, Brejo Verde e Boneco) do Município de Itanagra, litoral norte da Bahia, 13 táxons de Closteriaceae (gênero Closterium) e 39 táxons infraespecíficos de Desmidiaceae (gêneros Bambusina, Cosmarium, Desmidium, Euastrum, Hyalotheca, Micrasterias, Pleurotaenium, Spondylosium, Staurastrum, Staurodesmus e Tetmemorus).
O presente trabalho teve por objetivo realizar o inventário taxonômico do gênero Micrasterias em duas Áreas de Proteção Ambiental, a APA Lagoas de Guarajuba e a APA Rio Capivara, visando contribuir para o conhecimento da desmidioflórula do Estado da Bahia.

\section{Material e métodos}

A área de estudo localiza-se no município de Camaçari, Região Metropolitana de Salvador e abrange duas Áreas de Proteção Ambiental, a APA Lagoas de Guarajuba (com área de 230 ha) e a APA Rio Capivara (com área de 1.800 ha) (figura 1).

Foram coletadas 96 amostras, sendo 44 na APA Lagoas de Guarajuba e 52 na APA Rio Capivara (tabela 1). A coleta do material foi feita de acordo com os métodos usuais empregados nos estudos de taxonomia de microalgas continentais (Bicudo $\&$ Menezes 2006). As amostras de material planctônico foram coletadas com auxílio de rede feita de tecido de malha com $20 \mu \mathrm{m}$ de abertura. A rede foi passada na região litorânea de ambientes lóticos e lênticos, onde cresciam plantas aquáticas flutuantes e fixas. O material perifítico foi amostrado através do espremido manual de plantas inteiramente submersas ou de partes submersas delas, coletando o líquido resultante da espremedura em frasco de polietileno.

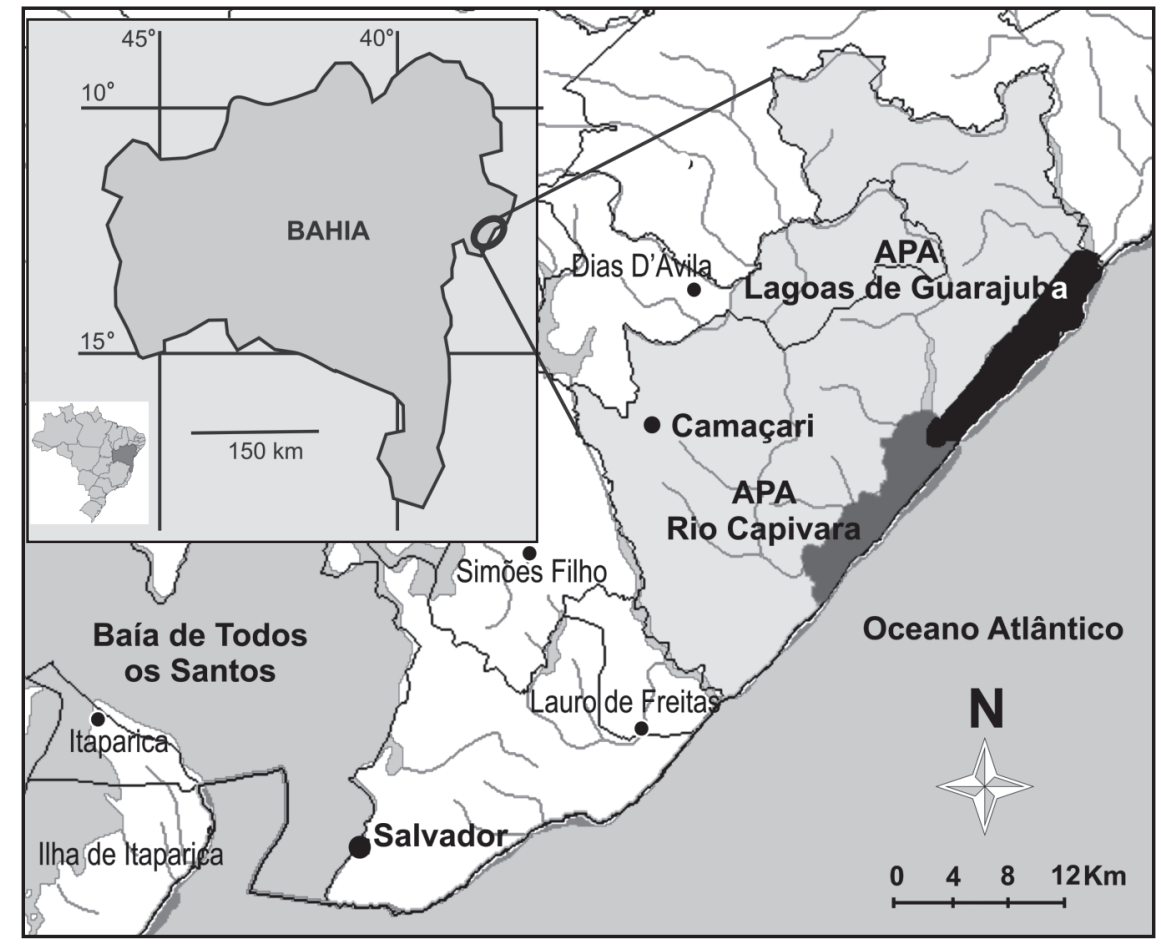

Figura 1. Mapa de localização do Estado da Bahia, município de Camaçari e as duas Áreas de Proteção Ambiental - APA Rio Capivara e APA Lagoas de Guarajuba.

Figure 1. Map of the Bahia state and Camaçari municipality and two areas of Environment Protection Areas - APA Rio Capivara and APA Lagoas de Guarajuba. 
Tabela 1. Estações de coletas de Micrasterias e suas respectivas coordenadas nas APAs Lagoas de Guarajuba e Rio Capivara, Município de Camaçari, Bahia, Brasil

Table 1. Stations of collections of Micrasterias and their coordinates in APAs Lagoas de Guarajuba and Rio Capivara, Camaçari, Bahia, Brazil

\begin{tabular}{|c|c|c|c|c|c|}
\hline Estações & APA & Coordenadas & Data & Coletores & $\begin{array}{l}\text { № Tombo } \\
\text { (HUEFS) }\end{array}$ \\
\hline 1 & Lagoas de Guarajuba & $\begin{array}{l}12^{\circ} 38^{\prime} 44,9^{\prime \prime} \mathrm{S} \\
38^{\circ} 03^{\prime} 55,9^{\prime} \mathrm{W}\end{array}$ & $12-\mathrm{I}-2007$ & I.B. Oliveira \& I.S. Oliveira & 125503 \\
\hline 2 & Lagoas de Guarajuba & $\begin{array}{l}12^{\circ} 38^{\prime} 55,1^{\prime}, \mathrm{S} \\
38^{\circ} 04^{\prime} 22,2^{\prime} \mathrm{W}\end{array}$ & $12-\mathrm{I}-2007$ & I.B. Oliveira \& I.S. Oliveira & 125504 \\
\hline 3 & Lagoas de Guarajuba & $\begin{array}{l}12^{\circ} 39^{\prime} 05,1^{\prime \prime} \mathrm{S} \\
38^{\circ} 04^{\prime} 22,0^{\prime \prime} \mathrm{W}\end{array}$ & $12-\mathrm{I}-2007$ & I.B. Oliveira \& I.S. Oliveira & 125505 \\
\hline 4 & Lagoas de Guarajuba & $\begin{array}{l}12^{\circ} 38^{\prime} 50,2^{\prime \prime} \mathrm{S} \\
38^{\circ} 04^{\prime} 08,2^{\prime \prime} \mathrm{W}\end{array}$ & $12-\mathrm{I}-2007$ & I.B. Oliveira \& I.S. Oliveira & 125506 \\
\hline 5 & Lagoas de Guarajuba & $\begin{array}{l}12^{\circ} 38^{\prime} 55,8^{\prime \prime} \mathrm{S} \\
38^{\circ} 04^{\prime} 18,5^{\prime} \mathrm{W}\end{array}$ & $12-\mathrm{I}-2007$ & I.B. Oliveira \& I.S. Oliveira & 125507 \\
\hline 6 & Lagoas de Guarajuba & $\begin{array}{l}12^{\circ} 38^{\prime} 49,8^{\prime \prime} \mathrm{S} \\
38^{\circ} 04^{\prime} 24,1^{\prime} \mathrm{W}\end{array}$ & $12-\mathrm{I}-2007$ & I.B. Oliveira \& I.S. Oliveira & 125508 \\
\hline 7 & Lagoas de Guarajuba & $\begin{array}{l}12^{\circ} 38^{\prime} 50,5^{\prime}, \mathrm{S} \\
38^{\circ} 04^{\prime} 27,7^{\prime} \mathrm{W}\end{array}$ & 12-I-2007 & I.B. Oliveira \& I.S. Oliveira & 125509 \\
\hline 8 & Lagoas de Guarajuba & $\begin{array}{l}12^{\circ} 44^{\prime} 06,6 ” \mathrm{~S} \\
38^{\circ} 09,52,3 ” \mathrm{~W}\end{array}$ & $12-\mathrm{I}-2007$ & I.B. Oliveira \& I.S. Oliveira & 125510 \\
\hline 9 & Rio Capivara & $\begin{array}{l}12^{\circ} 44^{\prime} 58,2^{\prime \prime} \mathrm{S} \\
38^{\circ} 10^{\prime} 05,6 ” \mathrm{~W}\end{array}$ & $12-\mathrm{I}-2007$ & I.B. Oliveira \& I.S. Oliveira & 125511 \\
\hline 10 & Rio Capivara & $\begin{array}{l}12^{\circ} 46^{\prime} 15,9 ” \mathrm{~S} \\
38^{\circ} 10^{\prime} 47,2^{\prime \prime} \mathrm{W}\end{array}$ & $12-\mathrm{I}-2007$ & I.B. Oliveira \& I.S. Oliveira & 125514 \\
\hline 11 & Rio Capivara & $\begin{array}{l}12^{\circ} 45^{\prime} 46,6^{\prime \prime} \mathrm{S} \\
38^{\circ} 10^{\prime} 15,6^{\prime \prime} \mathrm{W}\end{array}$ & $12-\mathrm{I}-2007$ & I.B. Oliveira \& I.S. Oliveira & 125516 \\
\hline 12 & Rio Capivara & $\begin{array}{l}12^{\circ} 45^{\prime} 48,1^{\prime \prime} \mathrm{S} \\
38^{\circ} 10^{\prime} 48,0^{\prime} \mathrm{W}\end{array}$ & $12-\mathrm{I}-2007$ & I.B. Oliveira \& I.S. Oliveira & 125517 \\
\hline 13 & Rio Capivara & $\begin{array}{l}12^{\circ} 45^{\prime} 18,8^{\prime \prime} \mathrm{S} \\
38^{\circ} 09,51,3 ” \mathrm{~W}\end{array}$ & $12-\mathrm{I}-2007$ & I.B. Oliveira \& I.S. Oliveira & 125518 \\
\hline 14 & Rio Capivara & $\begin{array}{l}12^{\circ} 45^{\prime} 21,1 ” \mathrm{~S} \\
38^{\circ} 099^{\prime} 52,0^{\prime \prime} \mathrm{W}\end{array}$ & $12-\mathrm{I}-2007$ & I.B. Oliveira \& I.S. Oliveira & 125519 \\
\hline 15 & Rio Capivara & $\begin{array}{l}12^{\circ} 45^{\prime} 23,6^{\prime \prime} \mathrm{S} \\
38^{\circ} 09^{\prime} 53,7^{\prime} \mathrm{W}\end{array}$ & $12-\mathrm{I}-2007$ & I.B. Oliveira \& I.S. Oliveira & 125520 \\
\hline 16 & Rio Capivara & $\begin{array}{l}12^{\circ} 45^{\prime} 22,9^{\prime}, \mathrm{S} \\
38^{\circ} 09^{\prime} 58,0^{\prime} \mathrm{W}\end{array}$ & $12-\mathrm{I}-2007$ & I.B. Oliveira \& I.S. Oliveira & 125521 \\
\hline 17 & Lagoas de Guarajuba & $\begin{array}{l}12^{\circ} 38^{\prime} 47,8^{\prime \prime} \mathrm{S} \\
38^{\circ} 04^{\prime} 04,2^{\prime} \mathrm{W}\end{array}$ & 09-III-2007 & $\begin{array}{l}\text { I.B. Oliveira, A.M. Alves \& } \\
\text { A.A. Santos }\end{array}$ & 125523 \\
\hline 18 & Lagoas de Guarajuba & $\begin{array}{l}12^{\circ} 38^{\prime} 50,6 ” \mathrm{~S} \\
38^{\circ} 04^{\prime} 08,7 ” \mathrm{~W}\end{array}$ & 09-III-2007 & $\begin{array}{l}\text { I.B. Oliveira, A.M. Alves \& } \\
\text { A.A. Santos }\end{array}$ & 125524 \\
\hline 19 & Lagoas de Guarajuba & $\begin{array}{l}12^{\circ} 38^{\prime} 49,7^{\prime \prime} \mathrm{S} \\
38^{\circ} 04^{\prime} 26,6^{\prime} \mathrm{W}\end{array}$ & 09-III-2007 & $\begin{array}{l}\text { I.B. Oliveira, A.M. Alves \& } \\
\text { A.A. Santos }\end{array}$ & 125525 \\
\hline 20 & Lagoas de Guarajuba & $\begin{array}{l}12^{\circ} 38^{\prime} 46,99^{\prime \prime} \mathrm{S} \\
38^{\circ} 04^{\prime} 27,99^{\prime} \mathrm{W}\end{array}$ & 09-III-2007 & $\begin{array}{l}\text { I.B. Oliveira, A.M. Alves \& } \\
\text { A.A. Santos }\end{array}$ & 125527 \\
\hline 21 & Lagoas de Guarajuba & $\begin{array}{l}12^{\circ} 40^{\prime} 01,6^{\prime} \mathrm{S} \\
38^{\circ} 05^{\prime} 17,2^{\prime} \mathrm{W}\end{array}$ & 09-III-2007 & $\begin{array}{l}\text { I.B. Oliveira, A.M. Alves \& } \\
\text { A.A. Santos }\end{array}$ & 125531 \\
\hline
\end{tabular}


continuação

\begin{tabular}{|c|c|c|c|c|c|}
\hline Estações & APA & Coordenadas & Data & Coletores & $\begin{array}{l}\text { № Tombo } \\
\text { (HUEFS) }\end{array}$ \\
\hline 22 & Lagoas de Guarajuba & $\begin{array}{l}12^{\circ} 40^{\prime} 00,7^{\prime}, \mathrm{S} \\
38^{\circ} 05^{\prime} 16,5^{\prime} \mathrm{W}\end{array}$ & 09-III-2007 & $\begin{array}{l}\text { I.B. Oliveira, A.M. Alves \& } \\
\text { A.A. Santos }\end{array}$ & 125532 \\
\hline 23 & Lagoas de Guarajuba & $\begin{array}{l}12^{\circ} 39^{\prime} 59,6 ” \mathrm{~S} \\
38^{\circ} 05^{\prime} 15,8^{\prime \prime} \mathrm{W}\end{array}$ & 09-III-2007 & $\begin{array}{l}\text { I.B. Oliveira, A.M. Alves \& } \\
\text { A.A. Santos }\end{array}$ & 125533 \\
\hline 24 & Lagoas de Guarajuba & $\begin{array}{l}12^{\circ} 39^{\prime} 57,7^{\prime \prime} \mathrm{S} \\
38^{\circ} 05^{\prime} 14,6^{\prime} \mathrm{W}\end{array}$ & 09-III-2007 & $\begin{array}{l}\text { I.B. Oliveira, A.M. Alves \& } \\
\text { A.A. Santos }\end{array}$ & 125534 \\
\hline 25 & Lagoas de Guarajuba & $\begin{array}{l}12^{\circ} 39^{\prime} 55,8^{\prime \prime} \mathrm{S} \\
38^{\circ} 05^{\prime} 13,5^{\prime} \mathrm{W}\end{array}$ & 09-III-2007 & $\begin{array}{l}\text { I.B. Oliveira, A.M. Alves \& } \\
\text { A.A. Santos }\end{array}$ & 125535 \\
\hline 26 & Lagoas de Guarajuba & $\begin{array}{l}12^{\circ} 39^{\prime} 54,0 ”, \mathrm{~S} \\
38^{\circ} 05^{\prime} 12,5^{\prime} \mathrm{W}\end{array}$ & 09-III-2007 & $\begin{array}{l}\text { I.B. Oliveira, A.M. Alves \& } \\
\text { A.A. Santos }\end{array}$ & 125536 \\
\hline 27 & Lagoas de Guarajuba & $\begin{array}{l}12^{\circ} 39^{\prime} 45,5^{\prime \prime} \mathrm{S} \\
38^{\circ} 05^{\prime} 05,2^{\prime} \mathrm{W}\end{array}$ & 09-III-2007 & $\begin{array}{l}\text { I.B. Oliveira, A.M. Alves \& } \\
\text { A.A. Santos }\end{array}$ & 125538 \\
\hline 28 & Lagoa de Guarajuba & $\begin{array}{l}12^{\circ} 39^{\prime} 53,6^{\prime \prime} \mathrm{S} \\
38^{\circ} 05^{\prime} 12,3 ” \mathrm{~W}\end{array}$ & 09-III-2007 & $\begin{array}{l}\text { I.B. Oliveira, A.M. Alves \& } \\
\text { A.A. Santos }\end{array}$ & 125539 \\
\hline 29 & Lagoas de Guarajuba & $\begin{array}{l}12^{\circ} 39^{\prime} 53,2^{\prime \prime} \mathrm{S} \\
38^{\circ} 05^{\prime} 13,7^{\prime} \mathrm{W}\end{array}$ & 09-III-2007 & $\begin{array}{l}\text { I.B. Oliveira, A.M. Alves \& } \\
\text { A.A. Santos }\end{array}$ & 125540 \\
\hline 30 & Lagoas de Guarajuba & $\begin{array}{l}12^{\circ} 39^{\prime} 50,8^{\prime \prime} \mathrm{S} \\
38^{\circ} 05^{\prime} 17,00^{\prime} \mathrm{W}\end{array}$ & 09-III-2007 & $\begin{array}{l}\text { I.B. Oliveira, A.M. Alves \& } \\
\text { A.A. Santos }\end{array}$ & 125543 \\
\hline 31 & Lagoas de Guarajuba & $\begin{array}{l}12^{\circ} 39^{\prime} 50,1^{\prime \prime} \mathrm{S} \\
38^{\circ} 05^{\prime} 19,1^{\prime} \mathrm{W}\end{array}$ & 09-III-2007 & $\begin{array}{l}\text { I.B. Oliveira, A.M. Alves \& } \\
\text { A.A. Santos }\end{array}$ & 125544 \\
\hline 32 & Rio Capivara & $\begin{array}{l}12^{\circ} 45^{\prime} 23,4^{\prime \prime} \mathrm{S} \\
38^{\circ} 09^{\prime} 55,99^{\prime} \mathrm{W}\end{array}$ & 09-III-2007 & $\begin{array}{l}\text { I.B. Oliveira, A.M. Alves \& } \\
\text { A.A. Santos }\end{array}$ & 125545 \\
\hline 33 & Rio Capivara & $\begin{array}{l}12^{\circ} 45^{\prime} 23,2^{\prime \prime} \mathrm{S} \\
38^{\circ} 09^{\prime} 56,0^{\prime} \mathrm{W}\end{array}$ & 09-III-2007 & $\begin{array}{l}\text { I.B. Oliveira, A.M. Alves \& } \\
\text { A.A. Santos }\end{array}$ & 125546 \\
\hline 34 & Rio Capivara & $\begin{array}{l}12^{\circ} 45^{\prime} 23,0^{\prime \prime} \mathrm{S} \\
38^{\circ} 09^{\prime} 55,8^{\prime \prime} \mathrm{W}\end{array}$ & 09-III-2007 & $\begin{array}{l}\text { I.B. Oliveira, A.M. Alves \& } \\
\text { A.A. Santos }\end{array}$ & 125547 \\
\hline 35 & Rio Capivara & $\begin{array}{l}12^{\circ} 45^{\prime} 22,0^{\prime \prime} \mathrm{S} \\
38^{\circ} 09^{\prime} 56,2^{\prime \prime} \mathrm{W}\end{array}$ & 09-III-2007 & $\begin{array}{l}\text { I.B. Oliveira, A.M. Alves \& } \\
\text { A.A. Santos }\end{array}$ & 125548 \\
\hline 36 & Rio Capivara & $\begin{array}{l}12^{\circ} 45^{\prime} 23,7^{\prime \prime} \mathrm{S} \\
38^{\circ} 09^{\prime} 54,1^{\prime \prime} \mathrm{W}\end{array}$ & 09-III-2007 & $\begin{array}{l}\text { I.B. Oliveira, A.M. Alves \& } \\
\text { A.A. Santos }\end{array}$ & 125549 \\
\hline 37 & Rio Capivara & $\begin{array}{l}12^{\circ} 45^{\prime} 26,2^{\prime \prime} \mathrm{S} \\
38^{\circ} 09^{\prime} 58,1^{\prime \prime} \mathrm{W}\end{array}$ & 09-III-2007 & $\begin{array}{l}\text { I.B. Oliveira, A.M. Alves \& } \\
\text { A.A. Santos }\end{array}$ & 125550 \\
\hline 38 & Rio Capivara & $\begin{array}{l}12^{\circ} 45^{\prime} 23,4{ }^{\prime \prime} \mathrm{S} \\
38^{\circ} 09^{\prime} 59,77^{\prime} \mathrm{W}\end{array}$ & 09-III-2007 & $\begin{array}{l}\text { I.B. Oliveira, A.M. Alves \& } \\
\text { A.A. Santos }\end{array}$ & 125551 \\
\hline 39 & Rio Capivara & $\begin{array}{l}12^{\circ} 45^{\prime} 25,5^{\prime \prime} \mathrm{S} \\
38^{\circ} 10^{\prime} 03,4^{\prime \prime} \mathrm{W}\end{array}$ & 09-III-2007 & $\begin{array}{l}\text { I.B. Oliveira, A.M. Alves \& } \\
\text { A.A. Santos }\end{array}$ & 125552 \\
\hline 40 & Rio Capivara & $\begin{array}{l}12^{\circ} 45^{\prime} 33,4^{\prime \prime} \mathrm{S} \\
38^{\circ} 10^{\prime} 06,1^{\prime \prime} \mathrm{W}\end{array}$ & 09-III-2007 & $\begin{array}{l}\text { I.B. Oliveira, A.M. Alves \& } \\
\text { A.A. Santos }\end{array}$ & 125553 \\
\hline 41 & Rio Capivara & $\begin{array}{l}12^{\circ} 45^{\prime} 37,2^{\prime \prime} \mathrm{S} \\
38^{\circ} 10^{\prime} 06,5^{\prime} \mathrm{W}\end{array}$ & 09-III-2007 & $\begin{array}{l}\text { I.B. Oliveira, A.M. Alves \& } \\
\text { A.A. Santos }\end{array}$ & 125554 \\
\hline 42 & Rio Capivara & $\begin{array}{l}12^{\circ} 45^{\prime} 39,7^{\prime \prime} \mathrm{S} \\
38^{\circ} 10^{\prime} 05,8^{\prime} \mathrm{W}\end{array}$ & 09-III-2007 & $\begin{array}{l}\text { I.B. Oliveira, A.M. Alves \& } \\
\text { A.A. Santos }\end{array}$ & 125555 \\
\hline 43 & Rio Capivara & $\begin{array}{l}12^{\circ} 45^{\prime} 47,6^{\prime \prime} \mathrm{S} \\
38^{\circ} 10^{\prime} 16,1^{\prime} \mathrm{W}\end{array}$ & 09-III-2007 & $\begin{array}{l}\text { I.B. Oliveira, A.M. Alves \& } \\
\text { A.A. Santos }\end{array}$ & 125556 \\
\hline 44 & Rio Capivara & $\begin{array}{l}12^{\circ} 45^{\prime} 49,5^{\prime \prime} \mathrm{S} \\
38^{\circ} 10^{\prime} 14,5^{\prime}, \mathrm{W}\end{array}$ & 09-III-2007 & $\begin{array}{l}\text { I.B. Oliveira, A.M. Alves \& } \\
\text { A.A. Santos }\end{array}$ & $\begin{array}{l}125557 \\
\text { continuc }\end{array}$ \\
\hline
\end{tabular}


continuação

\begin{tabular}{|c|c|c|c|c|c|}
\hline Estações & APA & Coordenadas & Data & Coletores & $\begin{array}{l}\text { № Tombo } \\
\text { (HUEFS) }\end{array}$ \\
\hline 45 & Rio Capivara & $\begin{array}{l}12^{\circ} 45^{\prime} 59,8^{\prime \prime} \mathrm{S} \\
38^{\circ} 10^{\prime} 20,8^{\prime} \mathrm{W}\end{array}$ & 09-III-2007 & $\begin{array}{l}\text { I.B. Oliveira, A.M. Alves \& } \\
\text { A.A. Santos }\end{array}$ & 125561 \\
\hline 46 & Rio Capivara & $\begin{array}{l}12^{\circ} 45^{\prime} 00,9^{\prime \prime} \mathrm{S} \\
38^{\circ} 10^{\prime} 22,3{ }^{\prime \prime} \mathrm{W}\end{array}$ & 09-III-2007 & $\begin{array}{l}\text { I.B. Oliveira, A.M. Alves \& } \\
\text { A.A. Santos }\end{array}$ & 125562 \\
\hline 47 & Rio Capivara & $\begin{array}{l}12^{\circ} 44^{\prime} 57,6^{\prime \prime} \mathrm{S} \\
38^{\circ} 10^{\prime} 03,3 " \mathrm{~W}\end{array}$ & 08-VI-2007 & $\begin{array}{l}\text { I.B. Oliveira, C.W.N. Moura, } \\
\text { G.J.P. Ramos \& U.C. Oliveira }\end{array}$ & 125563 \\
\hline 48 & Rio Capivara & $\begin{array}{l}12^{\circ} 45^{\prime} 09,9^{\prime \prime} \mathrm{S} \\
38^{\circ} 09^{\prime} 46,8^{\prime} \mathrm{W}\end{array}$ & 08-VI-2007 & $\begin{array}{l}\text { I.B. Oliveira, C.W.N. Moura, } \\
\text { G.J.P. Ramos \& U.C. Oliveira }\end{array}$ & 125565 \\
\hline 49 & Rio Capivara & $\begin{array}{l}12^{\circ} 45^{\prime} 10,8^{\prime \prime} \mathrm{S} \\
38^{\circ} 09^{\prime} 45,2^{\prime} \mathrm{W}\end{array}$ & 08-VI-2007 & $\begin{array}{l}\text { I.B. Oliveira, C.W.N. Moura, } \\
\text { G.J.P. Ramos \& U.C. Oliveira }\end{array}$ & 125566 \\
\hline 50 & Rio Capivara & $\begin{array}{l}12^{\circ} 44^{\prime} 55,0 ” \mathrm{~S} \\
38^{\circ} 09^{\prime} 56,0^{\prime \prime} \mathrm{W}\end{array}$ & 08-VI-2007 & $\begin{array}{l}\text { I.B. Oliveira, C.W.N. Moura, } \\
\text { G.J.P. Ramos \& U.C. Oliveira }\end{array}$ & 125567 \\
\hline 51 & Rio Capivara & $\begin{array}{l}12^{\circ} 44^{\prime} 30,3^{\prime \prime} \mathrm{S} \\
38^{\circ} 09^{\prime} 07,6^{\prime} \mathrm{W}\end{array}$ & 08-VI-2007 & $\begin{array}{l}\text { I.B. Oliveira, C.W.N. Moura, } \\
\text { G.J.P. Ramos \& U.C. Oliveira }\end{array}$ & 125568 \\
\hline 52 & Rio Capivara & $\begin{array}{l}12^{\circ} 44^{\prime} 24,6 ” \mathrm{~S} \\
38^{\circ} 09^{\prime} 03,11^{\prime \prime} \mathrm{W}\end{array}$ & 08-VI-2007 & $\begin{array}{l}\text { I.B. Oliveira, C.W.N. Moura, } \\
\text { G.J.P. Ramos \& U.C. Oliveira }\end{array}$ & 125569 \\
\hline 53 & Rio Capivara & $\begin{array}{l}12^{\circ} 44^{\prime} 14,7{ }^{\prime} \mathrm{S} \\
38^{\circ} 08^{\prime} 55,8^{\prime} \mathrm{W}\end{array}$ & 08-VI-2007 & $\begin{array}{l}\text { I.B. Oliveira, C.W.N. Moura, } \\
\text { G.J.P. Ramos \& U.C. Oliveira }\end{array}$ & 125570 \\
\hline 54 & Rio Capivara & $\begin{array}{l}12^{\circ} 44^{\prime} 09,6^{\prime \prime} \mathrm{S} \\
38^{\circ} 08^{\prime} 46,4^{\prime} \mathrm{W}\end{array}$ & 08-VI-2007 & $\begin{array}{l}\text { I.B. Oliveira, C.W.N. Moura, } \\
\text { G.J.P. Ramos \& U.C. Oliveira }\end{array}$ & 125571 \\
\hline 55 & Rio Capivara & $\begin{array}{l}12^{\circ} 43^{\prime} 56,33^{\prime} \mathrm{S} \\
38^{\circ} 08^{\prime} 42,8^{\prime} \mathrm{W}\end{array}$ & 08-VI-2007 & $\begin{array}{l}\text { I.B. Oliveira, C.W.N. Moura, } \\
\text { G.J.P. Ramos \& U.C. Oliveira }\end{array}$ & 125572 \\
\hline 56 & Rio Capivara & $\begin{array}{l}12^{\circ} 43^{\prime} 52,5^{\prime}, \mathrm{S} \\
38^{\circ} 08^{\prime} 34,0^{\prime} \mathrm{W}\end{array}$ & 08-VI-2007 & $\begin{array}{l}\text { I.B. Oliveira, C.W.N. Moura, } \\
\text { G.J.P. Ramos \& U.C. Oliveira }\end{array}$ & 125573 \\
\hline 57 & Lagoas de Guarajuba & $\begin{array}{l}12^{\circ} 40^{\prime} 39,99^{\prime} \mathrm{S} \\
38^{\circ} 05^{\prime} 50,2^{\prime} \mathrm{W}\end{array}$ & 08-VI-2007 & $\begin{array}{l}\text { I.B. Oliveira, C.W.N. Moura, } \\
\text { G.J.P. Ramos \& U.C. Oliveira }\end{array}$ & 125576 \\
\hline 58 & Lagoas de Guarajuba & $\begin{array}{l}12^{\circ} 40^{\prime} 19,4^{\prime \prime} \mathrm{S} \\
38^{\circ} 05^{\prime} 19,44^{\prime} \mathrm{W}\end{array}$ & 08-VI-2007 & $\begin{array}{l}\text { I.B. Oliveira, C.W.N. Moura, } \\
\text { G.J.P. Ramos \& U.C. Oliveira }\end{array}$ & 125580 \\
\hline 59 & Lagoas de Guarajuba & $\begin{array}{l}12^{\circ} 40^{\prime} 13,3^{\prime \prime} \mathrm{S} \\
38^{\circ} 05^{\prime} 32,8^{\prime} \mathrm{W}\end{array}$ & 08-VI-2007 & $\begin{array}{l}\text { I.B. Oliveira, C.W.N. Moura, } \\
\text { G.J.P. Ramos \& U.C. Oliveira }\end{array}$ & 125581 \\
\hline 60 & Lagoas de Guarajuba & $\begin{array}{l}12^{\circ} 40^{\prime} 09,3^{\prime \prime} \mathrm{S} \\
38^{\circ} 05^{\prime} 35,5^{\prime} \mathrm{W}\end{array}$ & 08-VI-2007 & $\begin{array}{l}\text { I.B. Oliveira, C.W.N. Moura, } \\
\text { G.J.P. Ramos \& U.C. Oliveira }\end{array}$ & 125582 \\
\hline 61 & Rio Capivara & $\begin{array}{l}12^{\circ} 45^{\prime} 12,9^{\prime \prime} \mathrm{S} \\
38^{\circ} 09^{\prime} 40,2^{\prime} \mathrm{W}\end{array}$ & 20-VII-2007 & $\begin{array}{l}\text { I.B. Oliveira, T.B. Oliveira \& } \\
\text { A.A. Santos }\end{array}$ & 125583 \\
\hline 62 & Rio Capivara & $\begin{array}{l}12^{\circ} 45^{\prime} 08,7^{\prime} \mathrm{S} \\
38^{\circ} 09^{\prime} 37,2^{\prime} \mathrm{W}\end{array}$ & 20-VII-2007 & $\begin{array}{l}\text { I.B. Oliveira, T.B. Oliveira \& } \\
\text { A.A. Santos }\end{array}$ & 125584 \\
\hline 63 & Rio Capivara & $\begin{array}{l}12^{\circ} 44^{\prime} 54,2^{\prime \prime} \mathrm{S} \\
38^{\circ} 09^{\prime} 26,1^{\prime} \mathrm{W}\end{array}$ & 20-VII-2007 & $\begin{array}{l}\text { I.B. Oliveira, T.B. Oliveira \& } \\
\text { A.A. Santos }\end{array}$ & 125585 \\
\hline 64 & Rio Capivara & $\begin{array}{l}12^{\circ} 44^{\prime} 49,8^{\prime \prime} \mathrm{S} \\
38^{\circ} 09^{\prime} 21,2^{\prime} \mathrm{W}\end{array}$ & 20-VII-2007 & $\begin{array}{l}\text { I.B. Oliveira, T.B. Oliveira \& } \\
\text { A.A. Santos }\end{array}$ & 125586 \\
\hline 65 & Rio Capivara & $\begin{array}{l}12^{\circ} 44^{\prime} 46,1^{\prime}, \mathrm{S} \\
38^{\circ} 09^{\prime} 17,8^{\prime} \mathrm{W}\end{array}$ & 20-VII-2007 & $\begin{array}{l}\text { I.B. Oliveira, T.B. Oliveira \& } \\
\text { A.A. Santos }\end{array}$ & 125587 \\
\hline 66 & Rio Capivara & $\begin{array}{l}12^{\circ} 44^{\prime} 33,8^{\prime \prime} \mathrm{S} \\
38^{\circ} 09^{\prime} 19,1^{\prime} \mathrm{W}\end{array}$ & 20-VII-2007 & $\begin{array}{l}\text { I.B. Oliveira, T.B. Oliveira \& } \\
\text { A.A. Santos }\end{array}$ & 125588 \\
\hline 67 & Rio Capivara & $\begin{array}{l}12^{\circ} 44^{\prime} 20,9^{\prime \prime} \mathrm{S} \\
38^{\circ} 09^{\prime} 02,2^{\prime \prime} \mathrm{W}\end{array}$ & 20-VII-2007 & $\begin{array}{l}\text { I.B. Oliveira, T.B. Oliveira \& } \\
\text { A.A. Santos }\end{array}$ & 125589 \\
\hline
\end{tabular}


continuação

\begin{tabular}{|c|c|c|c|c|c|}
\hline Estações & APA & Coordenadas & Data & Coletores & $\begin{array}{l}\text { № Tombo } \\
\text { (HUEFS) }\end{array}$ \\
\hline 68 & Rio Capivara & $\begin{array}{l}12^{\circ} 44^{\prime} 26,9^{\prime \prime} \mathrm{S} \\
38^{\circ} 09^{\prime} 10,8^{\prime \prime} \mathrm{W}\end{array}$ & 20-VII-2007 & $\begin{array}{l}\text { I.B. Oliveira, T.B. Oliveira \& } \\
\text { A.A. Santos }\end{array}$ & 125590 \\
\hline 69 & Lagoas de Guarajuba & $\begin{array}{l}12^{\circ} 39^{\prime} 24,3^{\prime \prime} \mathrm{S} \\
38^{\circ} 05^{\prime} 06,2^{\prime}, \mathrm{W}\end{array}$ & 20-VII-2007 & $\begin{array}{l}\text { I.B. Oliveira, T.B. Oliveira \& } \\
\text { A.A. Santos }\end{array}$ & 125591 \\
\hline 70 & Lagoas de Guarajuba & $\begin{array}{l}12^{\circ} 38^{\prime} 43,8^{\prime \prime} \mathrm{S} \\
38^{\circ} 03^{\prime} 56,2^{\prime} \mathrm{W}\end{array}$ & 20-VII-2007 & $\begin{array}{l}\text { I.B. Oliveira, T.B. Oliveira \& } \\
\text { A.A. Santos }\end{array}$ & 125592 \\
\hline 71 & Lagoas de Guarajuba & $\begin{array}{l}12^{\circ} 38^{\prime} 45,9^{\prime \prime} \mathrm{S} \\
38^{\circ} 03^{\prime} 59,2^{\prime} \mathrm{W}\end{array}$ & 20-VII-2007 & $\begin{array}{l}\text { I.B. Oliveira, T.B. Oliveira \& } \\
\text { A.A. Santos }\end{array}$ & 125593 \\
\hline 72 & Lagoas de Guarajuba & $\begin{array}{l}12^{\circ} 38^{\prime} 49,6^{\prime \prime} \mathrm{S} \\
38^{\circ} 04^{\prime} 06,2^{\prime \prime} \mathrm{W}\end{array}$ & 20-VII-2007 & $\begin{array}{l}\text { I.B. Oliveira, T.B. Oliveira \& } \\
\text { A.A. Santos }\end{array}$ & 125594 \\
\hline 73 & Lagoas de Guarajuba & $\begin{array}{l}12^{\circ} 38^{\prime} 40,1^{\prime \prime} \mathrm{S} \\
38^{\circ} 08^{\prime} 10,2^{\prime} \mathrm{W}\end{array}$ & 20-VII-2007 & $\begin{array}{l}\text { I.B. Oliveira, T.B. Oliveira \& } \\
\text { A.A. Santos }\end{array}$ & 125596 \\
\hline 74 & Lagoas de Guarajuba & $\begin{array}{l}12^{\circ} 38^{\prime} 35,2^{\prime \prime} \mathrm{S} \\
38^{\circ} 04^{\prime} 14,2^{\prime}, \mathrm{W}\end{array}$ & 20-VII-2007 & $\begin{array}{l}\text { I.B. Oliveira, T.B. Oliveira \& } \\
\text { A.A. Santos }\end{array}$ & 125597 \\
\hline 75 & Lagoas de Guarajuba & $\begin{array}{l}12^{\circ} 38^{\prime} 45,4^{\prime \prime} \mathrm{S} \\
38^{\circ} 04^{\prime} 22,2^{\prime \prime} \mathrm{W}\end{array}$ & 20-VII-2007 & $\begin{array}{l}\text { I.B. Oliveira, T.B. Oliveira \& } \\
\text { A.A. Santos }\end{array}$ & 125599 \\
\hline 76 & Rio Capivara & $\begin{array}{l}12^{\circ} 44^{\prime} 58,4^{\prime \prime} \mathrm{S} \\
38^{\circ} 10^{\prime} 05,33^{\prime} \mathrm{W}\end{array}$ & 20-VII-2007 & $\begin{array}{l}\text { I.B. Oliveira, T.B. Oliveira \& } \\
\text { A.A. Santos }\end{array}$ & 125600 \\
\hline 77 & Rio Capivara & $\begin{array}{l}12^{\circ} 44^{\prime} 54,99^{\prime} \mathrm{S} \\
38^{\circ} 10^{\prime} 04,2^{\prime} \mathrm{W}\end{array}$ & 20-VII-2007 & $\begin{array}{l}\text { I.B. Oliveira, T.B. Oliveira \& } \\
\text { A.A. Santos }\end{array}$ & 125601 \\
\hline 78 & Rio Capivara & $\begin{array}{l}12^{\circ} 44^{\prime} 56,1^{\prime \prime} \mathrm{S} \\
38^{\circ} 10^{\prime} 02,8^{\prime} \mathrm{W}\end{array}$ & 20-VII-2007 & $\begin{array}{l}\text { I.B. Oliveira, T.B. Oliveira \& } \\
\text { A.A. Santos }\end{array}$ & 125602 \\
\hline 79 & Rio Capivara & $\begin{array}{l}12^{\circ} 45^{\prime} 20,4 ” \mathrm{~S} \\
38^{\circ} 09,50,4{ }^{\prime}, \mathrm{W}\end{array}$ & 25-VIII-2007 & $\begin{array}{l}\text { I.B. Oliveira, I.S. Oliveira \& } \\
\text { T.B. Oliveira }\end{array}$ & 125603 \\
\hline 80 & Rio Capivara & $\begin{array}{l}12^{\circ} 45^{\prime} 14.1^{\prime \prime} \mathrm{S} \\
38^{\circ} 09^{\prime} 46,8^{\prime} \mathrm{W}\end{array}$ & 25-VIII-2007 & $\begin{array}{l}\text { I.B. Oliveira, I.S. Oliveira \& } \\
\text { T.B. Oliveira }\end{array}$ & 125604 \\
\hline 81 & Rio Capivara & $\begin{array}{l}12^{\circ} 45^{\prime} 11,2^{\prime \prime} \mathrm{S} \\
38^{\circ} 09^{\prime} 42,8^{\prime} \mathrm{W}\end{array}$ & 25-VIII-2007 & $\begin{array}{l}\text { I.B. Oliveira, I.S. Oliveira \& } \\
\text { T.B. Oliveira }\end{array}$ & 125605 \\
\hline 82 & Rio Capivara & $\begin{array}{l}12^{\circ} 45^{\prime} 26,1^{\prime \prime} \mathrm{S} \\
38^{\circ} 10^{\prime} 03,8^{\prime} \mathrm{W}\end{array}$ & 25-VIII-2007 & $\begin{array}{l}\text { I.B. Oliveira, I.S. Oliveira \& } \\
\text { T.B. Oliveira }\end{array}$ & 125606 \\
\hline 83 & Rio Capivara & $\begin{array}{l}12^{\circ} 45^{\prime} 31,7^{\prime \prime} \mathrm{S} \\
38^{\circ} 10^{\prime} 05,1^{\prime \prime} \mathrm{W}\end{array}$ & 25-VIII-2007 & $\begin{array}{l}\text { I.B. Oliveira, I.S. Oliveira \& } \\
\text { T.B. Oliveira }\end{array}$ & 125607 \\
\hline 84 & Rio Capivara & $\begin{array}{l}12^{\circ} 45^{\prime} 37,6^{\prime}, \mathrm{S} \\
38^{\circ} 10^{\prime} 07,3^{\prime} \mathrm{W}\end{array}$ & 25-VIII-2007 & $\begin{array}{l}\text { I.B. Oliveira, I.S. Oliveira \& } \\
\text { T.B. Oliveira }\end{array}$ & 125608 \\
\hline 85 & Rio Capivara & $\begin{array}{l}12^{\circ} 45^{\prime} 37,6^{\prime \prime} \mathrm{S} \\
38^{\circ} 10^{\prime} 07,33^{\prime} \mathrm{W}\end{array}$ & 25-VIII-2007 & $\begin{array}{l}\text { I.B. Oliveira, I.S. Oliveira \& } \\
\text { T.B. Oliveira }\end{array}$ & 125609 \\
\hline 86 & Rio Capivara & $\begin{array}{l}12^{\circ} 46^{\prime} 00,5^{\prime \prime} \mathrm{S} \\
38^{\circ} 10^{\prime} 22,8^{\prime} \mathrm{W}\end{array}$ & 25-VIII-2007 & $\begin{array}{l}\text { I.B. Oliveira, I.S. Oliveira \& } \\
\text { T.B. Oliveira }\end{array}$ & 125610 \\
\hline 87 & Lagoas de Guarajuba & $\begin{array}{l}12^{\circ} 39^{\prime} 48,9^{\prime \prime} \mathrm{S} \\
38^{\circ} 05^{\prime} 21,99^{\prime \prime} \mathrm{W}\end{array}$ & 25-VIII-2007 & $\begin{array}{l}\text { I.B. Oliveira, I.S. Oliveira \& } \\
\text { T.B. Oliveira }\end{array}$ & 125611 \\
\hline 88 & Lagoas de Guarajuba & $\begin{array}{l}12^{\circ} 39^{\prime} 55,6 ” \mathrm{~S} \\
38^{\circ} 05^{\prime} 14,99^{\prime} \mathrm{W}\end{array}$ & 25-VIII-2007 & $\begin{array}{l}\text { I.B. Oliveira, I.S. Oliveira \& } \\
\text { T.B. Oliveira }\end{array}$ & 125614 \\
\hline 89 & Lagoas de Guarajuba & $\begin{array}{l}12^{\circ} 39^{\prime} 53,6 ” \mathrm{~S} \\
38^{\circ} 05^{\prime} 16,3 ” \mathrm{~W}\end{array}$ & 25-VIII-2007 & $\begin{array}{l}\text { I.B. Oliveira, I.S. Oliveira \& } \\
\text { T.B. Oliveira }\end{array}$ & 125615 \\
\hline 90 & Lagoas de Guarajuba & $\begin{array}{l}12^{\circ} 39^{\prime} 51,5^{\prime \prime} \mathrm{S} \\
38^{\circ} 05^{\prime} 18,8^{\prime}, \mathrm{W}\end{array}$ & 25-VIII-2007 & $\begin{array}{l}\text { I.B. Oliveira, I.S. Oliveira \& } \\
\text { T.B. Oliveira }\end{array}$ & $\begin{array}{l}125616 \\
\text { continua }\end{array}$ \\
\hline
\end{tabular}


continuação

\begin{tabular}{|c|c|c|c|c|c|}
\hline Estações & APA & Coordenadas & Data & Coletores & $\begin{array}{l}\text { № Tombo } \\
\text { (HUEFS) }\end{array}$ \\
\hline 91 & Lagoas de Guarajuba & $\begin{array}{l}12^{\circ} 39^{\prime} 46,4^{\prime \prime} \mathrm{S} \\
38^{\circ} 05^{\prime} 23,3^{\prime} \mathrm{W}\end{array}$ & 25-VIII-2007 & $\begin{array}{l}\text { I.B. Oliveira, I.S. Oliveira \& } \\
\text { T.B. Oliveira }\end{array}$ & 125617 \\
\hline 92 & Lagoas de Guarajuba & $\begin{array}{l}12^{\circ} 39^{\prime} 47,2^{\prime \prime} \mathrm{S} \\
38^{\circ} 05^{\prime} 23,9^{\prime} \mathrm{W}\end{array}$ & 25-VIII-2007 & $\begin{array}{l}\text { I.B. Oliveira, I.S. Oliveira \& } \\
\text { T.B. Oliveira }\end{array}$ & 125618 \\
\hline 93 & Lagoas de Guarajuba & $\begin{array}{l}12^{\circ} 38^{\prime} 51,5^{\prime}, \mathrm{S} \\
38^{\circ} 04^{\prime} 21,8^{\prime} \mathrm{W}\end{array}$ & 25-VIII-2007 & $\begin{array}{l}\text { I.B. Oliveira, I.S. Oliveira \& } \\
\text { T.B. Oliveira }\end{array}$ & 125619 \\
\hline 94 & Lagoas de Guarajuba & $\begin{array}{l}12^{\circ} 38^{\prime} 53,6^{\prime \prime} \mathrm{S} \\
38^{\circ} 04^{\prime} 17,3^{\prime \prime} \mathrm{W}\end{array}$ & 25-VIII-2007 & $\begin{array}{l}\text { I.B. Oliveira, I.S. Oliveira \& } \\
\text { T.B. Oliveira }\end{array}$ & 125620 \\
\hline 95 & Lagoas de Guarajuba & $\begin{array}{l}12^{\circ} 38^{\prime} 50,1^{\prime \prime} \mathrm{S} \\
38^{\circ} 04^{\prime} 15,3^{\prime \prime} \mathrm{W}\end{array}$ & 25-VIII-2007 & $\begin{array}{l}\text { I.B. Oliveira, I.S. Oliveira \& } \\
\text { T.B. Oliveira }\end{array}$ & 125621 \\
\hline 96 & Lagoas de Guarajuba & $\begin{array}{l}12^{\circ} 38^{\prime} 53,9^{\prime \prime} \mathrm{S} \\
38^{\circ} 04^{\prime} 18,9^{\prime}, \mathrm{W}\end{array}$ & 25-VIII-2007 & $\begin{array}{l}\text { I.B. Oliveira, I.S. Oliveira \& } \\
\text { T.B. Oliveira }\end{array}$ & 125622 \\
\hline
\end{tabular}

As características métricas das populações foram tomadas através de ocular micrométrica acoplada ao microscópio óptico e as identificações das espécies baseadas em literatura especializada.

As amostras foram preservadas em solução de Transeau preparada conforme Bicudo \& Menezes (2006) e tombadas na coleção líquida do Herbário da Universidade Estadual de Feira de Santana (HUEFS).

\section{Resultados e discussão}

Micrasterias C. Agardh ex Ralfs

O gênero é constituído por indivíduos unicelulares, cujas células podem ser solitárias ou reunirem-se em uma série linear, formando filamentos simples como em Micrasterias foliacea Bailey ex Ralfs. As células são pouco mais longas do que largas, raramente tão longas quanto largas ou mais largas do que longas, possuem contorno elíptico a circular, achatadas frontalmente, simétricas, profundamente constritas na parte média. O seno mediano divide a célula em duas metades idênticas e pode ser linear e apertado ou, mais raramente, acutangular. As semicélulas podem ser 3 ou 5-lobadas, sendo o lobo polar sempre cuneiforme-alongado, chanfrado ou profundamente entalhado no ápice, às vezes lateralmente expandido, de modo a aparecer transversalmente fusiforme, porém, jamais subdividido; os lobos laterais e os basais são, freqüentemente, subdivididos em lóbulos por meio de incisões de profundidades variadas. A parede celular pode ser lisa, pontuada ou, algumas vezes, adornada com espinhos e, não raras vezes, provida de protuberâncias dispostas na base das semicélulas, as quais podem ou não ser decoradas com espinhos. A seção transversal mediana da célula é elíptico-fusiforme, os pólos são acuminados e podem ocorrer uma ou mais intumescências medianas de cada lado. O cloroplastídio é único por semicélula, axial, freqüentemente lobado, acompanhando o contorno da célula, com os pirenóides dispostos desordenadamente.

Chave artificial para a identificação das espécies, variedades e formas taxonômicas encontradas:

1. Células unidas formando filamentos

M. foliacea var. foliacea

1. Células solitárias

2. Células 3-lobadas

3. Incisão interlobar não acutangular

M. alata

3. Incisão interlobar acutangular

4. Extremidades do lobo polar bífidas

M. pinnatifida var. pinnatifida f. pinnatifida

4. Extremidades do lobo polar não bífidas

5. Extremidade do lobo basal bífida

M. laticeps. var. laticeps

5. Extremidade do lobo basal acuminada

6. Lobos basais e apicais desiguais M. arcuata var. subpinnatifida f. subpinnatifida

6. Lobos basais e apicais aproximadamente iguais M. laticeps var. acuminata 
2. Células 5-lobadas

7. Lobo polar com processos acessórios

8. Margem da célula não serrilhada .

M. americana var. bahiensis

8. Margem da célula serrilhada

9. Célula com seno acutangular

M. mahabuleswarensis var. mahabuleshwarensis f. mahabuleshwarensis

9. Célula com seno retilíneo M. mahabuleswarensis var. ampullacea

7. Lobo polar sem processos acessórios

10.Parede celular com espinhos organizados em fileiras ao longo das incisões

celulares, além de alguns esparsos acima do istmo

M. borgei var. borgei

10.Parede celular sem espinhos organizados em fileiras ao longo das incisões

celulares e sem espinhos acima do istmo

11.Incisões interlobares lineares

12.Lobos laterais e basais divididos de forma igual

M. radiosa var. elegantior

12. Lobos laterais e basais divididos de forma desigual M. rotata var. rotata 11.Incisões interlobares não lineares

13. Margem apical do lobo polar côncava M. truncata var. pusilla

13.Margem apical do lobo polar convexa M. furcata var. furcata f. furcata

Micrasterias alata G. C. Wall. Annl. Mag. Nat. Hist. 3, 5(28):279, pl. 13, fig. 11. 1860.

Figura 2

Célula 1,1-1,7 vezes mais longa que larga ou tão longa quanto larga, 187,5-192 $\mu \mathrm{m}$ compr., 174-180 $\mu \mathrm{m}$ larg., lobo polar 98-102 $\mu \mathrm{m}$ larg., istmo 20-25 $\mu \mathrm{m}$ larg., contorno subcircular, constrição mediana profunda, seno mediano linear próximo do istmo, acutangular na extremidade; semicélulas 3-lobadas, incisões interlobares não acutangulares, lobo polar subcilíndrico, margens laterais paralelas entre si ou quase, margem superior levemente côncava, divergindo em 2 processos, ângulos 3-denticulados, lobos basais divididos em 3 lóbulos por 2 incisões medianas profundas, abertas, acutangulares, ângulos terminando em (2-)3 dentículos; parede celular hialina, finamente pontuada; vistas apical e lateral fusiformes; cloroplastídio seguindo a forma da semicélula, pirenóides vários, esparsos.

Distribuição geográfica no Estado da Bahia - Primeira citação de ocorrência da espécie.

Ocorrência na área de estudo: BRASIL. BAHIA: Camaçari, APA Lagoas de Guarajuba (Estações 1, 3, 4, 6, 17, 20, 27, 30, 59, 60, 69, 70, 73, 88, 89, 91, 94); APA Rio Capivara (Estações 11, 12, 13, 15, 16, 31, 32, $33,34,35,36,37,39,41,42,43,44,45,47,48,49$, $50,51,52,53,54,55,56,68,76,86)$.

Grönblad (1945) registrou, pela primeira vez, a ocorrência desta espécie no território brasileiro.

Prescott et al. (1977), apresentaram variação morfológica quanto à espessura dos lobos polares e laterais e às incisões interlobares ora mais ora menos profundas, enquanto que Croasdale \& Flint (1986), registraram as extremidades 3-4-denticuladas. Nas populações analisadas, os exemplares apresentaram-se bem uniformes, sem variação morfológica, facilitando, assim, sua identificação.

Os presentes exemplares de Micrasterias alata diferem dos apresentados por Förster (1969), para a Amazônia em suas medidas celulares, que são pouco maiores (237-252 $\mu \mathrm{m}$ compr., 212-224 $\mu \mathrm{m}$ larg.). Contudo, concordam com a descrição, medidas e ilustrações em Krieger (1939) para material da Europa, Prescott et al. (1977), para material da América do Norte e por Croasdale \& Flint (1986), para material da Nova Zelândia.

Micrasterias americana (Ehrenb.) Ralfs var. bahiensis I. B. Oliveira, C. E. M. Bicudo \& C. W. N. Moura, var. nov. Typus: BRASILIA. Provincia Bahiae, Municipium Camaçari, 12³8’15,1”' S, 3804'21,8” W, 25-VIII-2007, lectus I.B.Oliveira, I.S. Oliveira \& T.B.Oliveira s.n. (holotypus HUEFS125619).

Figuras 3-4

Haec varietas a typo speciei differt lobos basales et laterales cum lobulis superioribus quam inferioribus minus projectis, seriebus granulorum in incisura interlobulata praesertim in extremitatibus lobulorum prope marginem apicalem lobi polari.

Célula 1,1-1,2 vezes mais longa que larga, 130$150 \mu \mathrm{m}$ compr., $119-130 \mu \mathrm{m}$ larg., lobo polar 72,5-87,5 $\mu \mathrm{m}$ larg., istmo 25-26 $\mu \mathrm{m}$ larg., contorno elíptico, constrição mediana profunda, seno mediano linear, levemente aberto 
em quase toda extensão; semicélulas 5-lobadas, incisões interlobares lineares, moderadamente profundas, lobo apical quase cilíndrico na parte basal, bastante divergente na parte distal, pouco projetado além dos lobos laterais, margens laterais quase retilíneas, logo amplamente divergentes, margem superior levemente côncava, retusa no meio, ornamentada com pequenos dentículos, 1 par de processos acessórios, curtos, dispostos assimetricamente 1 em cada lado do lobo polar, ângulos 3-denticulados, dentículos curtos, lobos laterais e basais cuneados, laterais menores, subdivididos por 1 leve, porém nítida incisão, aberta, originando 2 lóbulos desiguais, lóbulo inferior maior, encimado por 4 dentículos, lóbulo superior menor, encimado por 2 dentículos; lobos basais maiores, 2-lobulados, lóbulos desiguais entre si, incisão interlobular rasa, aberta, lóbulo inferior maior, encimado por 4 dentículos, lóbulo superior menor, encimado por 3 dentículos; parede celular hialina, ornamentada por
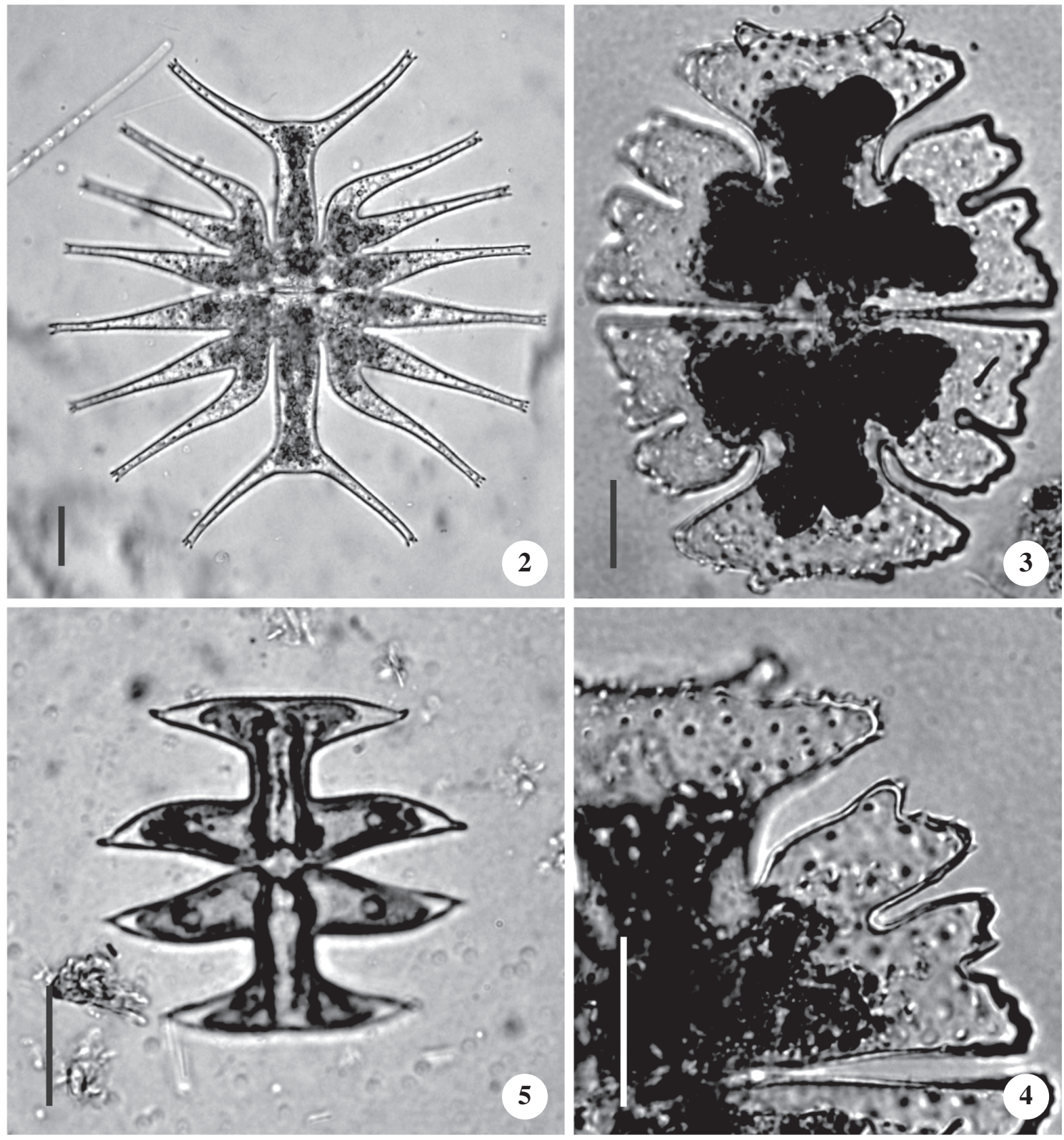

Figuras. 2-5. 2. Micrasterias alata. 3-4. M. americana var. bahiensis I. B. Oliveira et al., var. nov. 3. Aspecto geral. 4. Detalhe das verrugas. 5. M. arcuata var. subpinnatifida f. subpinnatifida. $($ Barra $=20 \mu \mathrm{m})$

Figures. 2-5. 2. Micrasterias alata. 3-4. M. americana var. bahiensis I. B. Oliveira et al., var. nov. 3. General aspect. 4. Detail the wart. 5. M. arcuata var. subpinnatifida f. subpinnatifida. $($ Bar $=20 \mu \mathrm{m})$ 
grânulos distribuídos ao longo das incisões interlobares e istmial, além de alguns de distribuição desordenada nos lobos laterais e apical, onde estão mais concentrados; vista apical não observada; vista lateral aproximadamente elíptica, estreita; cloroplastídio seguindo o contorno da célula; pirenóides vários, esparsos pelo cloroplastídio.

Micrasterias americana (Ehrenb.) Ralfs var. americana jamais foi citada para o território brasileiro. Há, contudo, registro da Micrasterias americana (Ehrenb.) Ralfs var. boldtii Gutw. feito por Sophia (1989), para o Estado do Rio de Janeiro.

Os espécimes examinados diferem de todas as variedades e formas taxonômicas descritas de Micrasterias americana por apresentarem lóbulos superiores menores que os inferiores, tanto dos lobos basais quanto dos laterais e fileiras de grânulos seguindo as incisões interlobares, porém, mais concentrados nas extremidades dos lóbulos, especialmente próximo da margem apical do lobo polar.

Micrasterias americana var. bahiense foi registrada em apenas uma unidade amostral (HUEFS 125619), porém, de forma abundante. $\mathrm{O}$ exame dessa população permitiu concluir que a morfologia geral das células é bastante estável, não apresentando polimorfismo.

Micrasterias arcuata Bailey var. subpinnatifida West \& G. S. West f. subpinnatifida Journ. Bot. 35:86, pl. 366, fig. 7. 1897.

Figura 5

Célula 1-1,1 vezes mais larga que longa, 63-77,5 $\mu \mathrm{m}$ compr., 69-82,5 $\mu \mathrm{m}$ larg., lobo polar 48-57,5 $\mu \mathrm{m}$ larg., istmo 10-14,5 $\mu \mathrm{m}$ larg., contorno aproximadamente elíptico, profundamente constrita na parte mediana, seno mediano amplamente aberto, profundo, abrindo para as extremidades acutangulares; semicélulas 3-lobadas, lobo polar em forma de "T", projeções laterais voltadas para cima ou para baixo, margem superior levemente convexa, ligeiramente retusa no meio, lobos basais lunados, mais largos que o lobo polar, mais ou menos curvados para cima, ângulos acuminados; parede celular finamente pontuada; vista vertical fusiforme; cloroplastídio preenchendo todo e espaço celular; pirenóides vários, esparsos.

Distribuição geográfica no Estado da Bahia - Em literatura: Serra das Almas, limite entre Bahia e Minas Gerais (Förster 1964: como Micrasterias arcuata West \& G. S. West var. subpinnatifida West \& G. S. West f. eckertii K. Först.).

Ocorrência na área de estudo: BRASIL. BAHIA: Camaçari, APA Lagoas de Guarajuba (Estações 18, 19,
21, 22, 23, 28, 29, 31, 70, 74, 88, 91, 95); APA Rio Capivara (Estações 39, 40, 47, 49, 77, 79, 80, 85).

A presente variedade difere da típica da espécie, especialmente, por possuir os lobos basais de ambas as semicélulas paralelos ou quase entre si, além da margem superior do lobo polar, em geral, paralela à margem superior do lobo basal, além dos indivíduos serem mais robustos do que os da variedade-tipo.

Sormus (1980) colocou a f. gracilis proposta por Förster (1964) na sinonímia da típica devido à observação de indivíduos intermediários quanto à convergência dos lobos e à ornamentação da parede. Nas amostras analisadas, essas formas intermediárias não foram observadas.

Micrasterias arcuata var. subpinnatifida $\mathrm{f}$. subpinnatifida é muito semelhante a Micrasterias arcuata Bailey var. subcornuta K. Först., diferindo desta, segundo Bicudo \& Sormus (1982), apenas pelo zigósporo, cuja parede é papilada na última variedade. No presente material, não foram observados zigósporos, porém, consideramos esses indivíduos idênticos a $M$. arcuata var. subpinnatifida f. subpinnatifida com base nas maiores semelhanças de certas características morfológicas vegetativas, como: 1) lobo polar em forma de "T" e 2) lobos basais de ambas semicélulas paralelos entre si.

As populações estudadas concordam com as descrições e ilustrações de $M$. arcuata var. subpinnatifida $\mathrm{f}$. subpinnatifida em Krieger (1939), para exemplares do Brasil (sem localidade definida), Förster (1964), para exemplares do Rio das Fêmeas, Porta Azul, Estado de Goiás, Lopes (1992), para exemplares da Amazônia e por Bicudo \& Sormus (1982), para exemplares do Estado de São Paulo.

Micrasterias borgei $\mathrm{H}$. Krieg. var. borgei In Rabenhorst, Kryptogamen-Fl. Deutschl. 13(2):86, pl. 128, fig. 1-4. 1939.

Figuras 6-7

Célula 1,1-1,2 vezes mais longa que larga, 248,5$260 \mu \mathrm{m}$ compr., 212,5-215 $\mu \mathrm{m}$ larg., lobo polar 76,5-78 $\mu \mathrm{m}$ larg., istmo 32-40 um larg., contorno elíptico; constrição mediana profunda, seno mediano linear, estreito, fechado em quase toda extensão, aberto na parte distal; semicélulas 5-lobadas, incisões interlobares lineares, acutangulares, lobo apical cuneiforme, pouco projetado além dos lobos laterais, margens laterais quase retilíneas, divergentes na porção superior, margem superior côncava, emarginada, chanfrada, 1 intumescência lisa em cada lado da chanfradura, ângulos com projeções divergentes, ápice 2-denticulados, dentículos internos maiores, curvos, dentículos externos retos, lobos laterais maiores 
que os basais, subdivididos em 8 lóbulos aproximadamente iguais entre si, levemente dilatados nas extremidades, 2-denticulados, dentículos retos ou ligeiramente divergentes, lobos basais subdivididos em 4 lóbulos aproximadamente iguais entre si, 2-denticulados, dentículos retos ou ligeiramente divergentes; parede celular hialina, finamente pontuada, ornamentada com espinhos distribuídos desordenadamente nos lobos apical e laterais e na suave intumescência acima do istmo, em fileiras intramarginais ao longo do seno mediano e das incisões mais profundas; vista apical não observada; vista lateral aproximadamente elíptica, estreita; cloroplastídio seguindo o contorno da célula; pirenóides vários, esparsos por todo plastídio.
Distribuição geográfica no Estado da Bahia - Em literatura: sem referências, primeira citação de ocorrência da espécie para o Estado.

Ocorrência na área de estudo: BRASIL. BAHIA: Camaçari, APA Lagoas de Guarajuba (Estação 95); APA Rio Capivara (Estações 62, 66, 77, 83).

O primeiro registro da ocorrência de Micrasterias borgei no território brasileiro está em Borge (1918: pl. 5, figura 34), que a escreveu e ilustrou como uma forma de M. apiculata (Ehrenb.) Ralfs, a partir de material coletado em Pirassununga, Estado de São Paulo. Apesar da ilustração de Borge (1918) assemelhar-se à de $M$. borgei var. borgei, Krieger (1939) não a relacionou entre os sinônimos propostos para sua nova espécie.
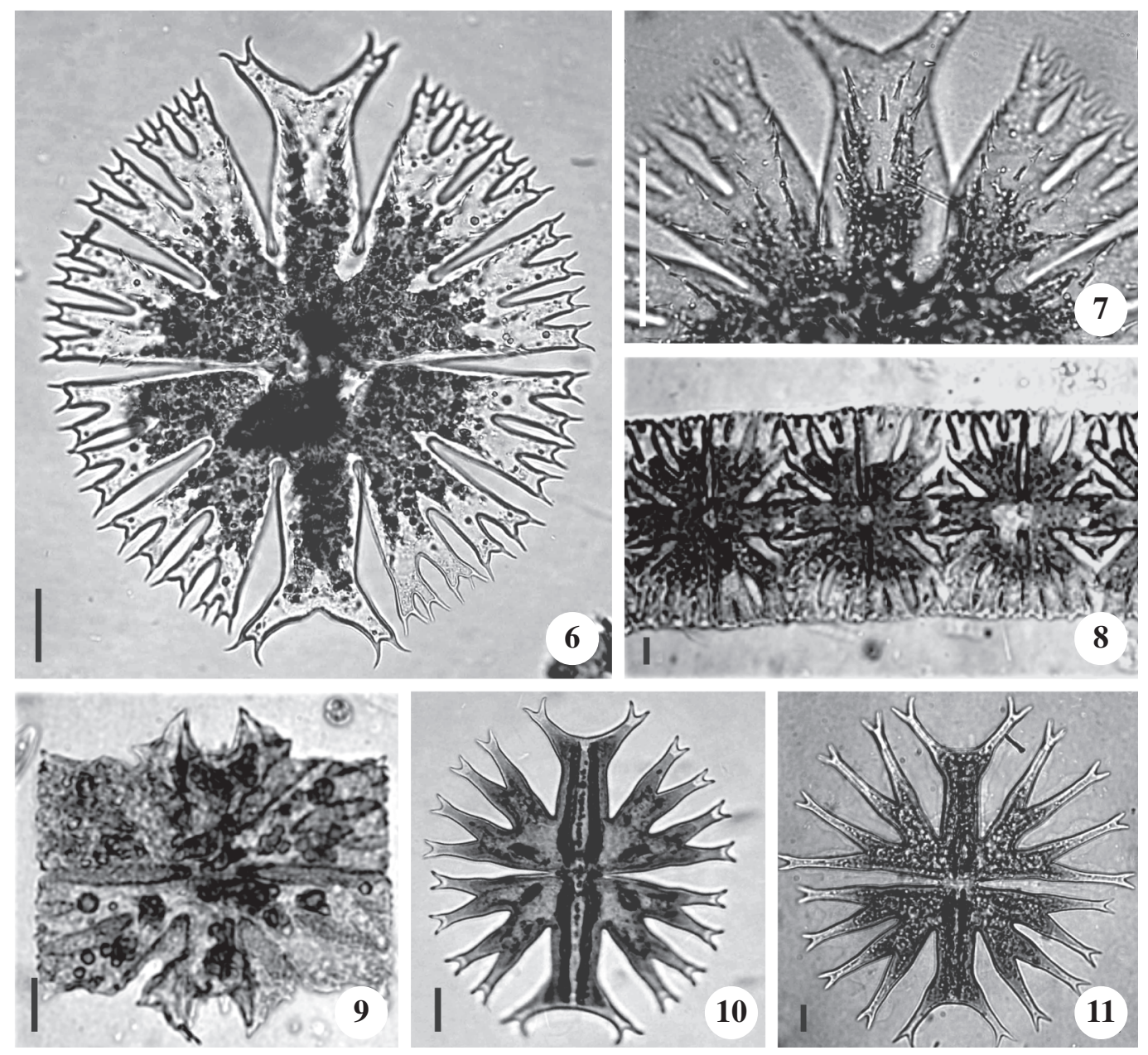

Figuras 6-11. 6-7. Micrasterias borgei var. borgei. 6. Aspecto geral da célula. 7. Detalhe dos espinhos da parede. 8-9. M. foliacea var. foliacea. 8. Aspecto geral de um filamento. 9. Detalhe da célula. 10-11. Variação morfológica de M. furcata var. furcata f. furcata. $($ Barra $=20 \mu \mathrm{m})$

Figures 6-11. 6-7. Micrasterias borgei var. borgei. 6. General aspect of cell. 7. Detail of spines. 8-9. M. foliacea var. foliacea. 8. General aspect of filament. 9. Detail of cell. 10-11. Morphological variation of M. furcata var. furcata f. furcata. $($ Bar $=20 \mu \mathrm{m})$ 
Em Förster (1969) consta, pela primeira vez, o registro da espécie como M. borgei Krieg. var. borgei a partir de material coletado no Estado do Pará.

Bicudo \& Sormus (1982) comentaram a discordância morfológica do material do Estado de São Paulo, entre outros, com o descrito em Förster $(1969,1974)$, relatando que o material identificado pelo último autor poderia ser M. borgei $\mathrm{H}$. Krieg. var. aequalis $\mathrm{H}$. Krieg. e Thomasson (1971) que propôs a f. minor baseado apenas nas medidas de um único exemplar.

O material analisado concorda com as descrições, medidas e ilustrações apresentadas por Borge (1918), para material do Estado do Pará, Krieger (1939), para material da Europa e Bicudo \& Sormus (1982), para material do Estado de São Paulo.

Micrasterias foliacea Bailey ex Ralfs var. foliacea Brit. Desmidieae 210, pl. 35, fig. 3. 1848.

Figuras 8-9

Filamento não torcido, célula 1,1-1,2 vezes mais larga que longa, 87,5-96 $\mu \mathrm{m}$ compr., 97-114,5 $\mu \mathrm{m}$ larg., lobo polar 32,5-40 $\mu \mathrm{m}$ larg., istmo 10-18 $\mu \mathrm{m}$ larg., aderida uma à outra por processos dos lobos polares, contorno retangular, constrição mediana profunda, seno mediano sublinear a acutangular, às vezes fechado na extremidade distal; lobo polar pouco projetado além dos lobos laterais, cilíndrico na parte basal, abrindo decididamente na parte distal, margens laterais convexas, margem apical bastante côncava, ângulos terminando em 2 dentes grosseiros, amplamente divergentes, 1 dos dentes projetado horizontalmente, o outro verticalmente, porção côncava do ápice apresentando 2 espinhos de cada lado, verticais, tamanhos desiguais entre si, que unem 1 célula à vizinha pelo imbricamento dos espinhos, lobos laterais divididos assimetricamente, lobos inferiores e basais 2-denticulados ou emarginados, lobos basais e horizontais 2-lobulados, cada lóbulo com 1 leve incisão mediana; parede celular hialina, lisa; cloroplastídio acompanhando o contorno celular, pirenóides vários, esparsos.

Distribuição geográfica no Estado da Bahia - Primeira citação de ocorrência da espécie para o Estado.

Ocorrência na área de estudo: BRASIL. BAHIA: Camaçari, APA Lagoas de Guarajuba (Estações 7, 8, 58, 94, 95, 96); APA Rio Capivara (Estações 9, 49, 51, $80,81,82,85)$.

Bicudo \& Sormus (1982) fizeram o primeiro registro da ocorrência da variedade típica da espécie no Brasil e, mais especificamente, para o Estado de São Paulo.
Micrasterias foliacea var. foliacea é uma espécie de fácil identificação por apresentar: 1) organização dos espinhos e 2) união das células em filamentos através do imbricamento dos espinhos dos lobos polares. Segundo Prescott et al. (1977), esses filamentos podem ser constituídos por até 182 células.

Os exemplares analisados concordam com as descrições e ilustrações apresentadas por Krieger (1939), para espécimes da Europa, Prescott et al. (1977), para espécimes da América do Norte e Bicudo \& Sormus (1982), para espécimes do Estado de São Paulo. A diferença está em apresentarem as medidas celulares pouco maiores.

Micrasterias furcata C. Agardh ex Ralfs var. furcata $\mathrm{f}$. furcata Brit. Desmidieae 73, pl. 9, fig. 2. 1848.

Figuras 10-11

Célula tão larga quanto longa, 150-162,5 $\mu \mathrm{m}$ compr.,

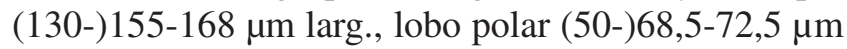
larg., istmo 17-20(-25) $\mu \mathrm{m}$ larg., contorno subcircular, constrição mediana profunda, seno mediano fechado próximo ao istmo, depois aberto, distalmente acutangular; semicélulas 5-lobadas, incisões interlobares profundas, acutangulares, abertas, lobo polar projetado além dos lobos laterais, margens laterais retilíneas ou quase até a metade, depois divergentes, margem superior cônvexa, ângulos formando processos divergentes, extremidades 2-denticuladas, dentículos divergentes, lobos basais e laterais iguais entre si, separados por 1 incisão profunda, aberta, cada lobo subdividido em 2 lóbulos delgados, ângulos 2-denticulados, dentículos às vezes divergentes; parede celular hialina, lisa, às vezes finamente pontuada; vista apical fusiforme, com 1 intumescência suave na parte mediana, pólos acuminados; vista lateral fusiforme; cloroplastídios seguindo a forma da semicélula, às vezes com lamelas dispostas irregularmente; pirenóides vários, dispersos, mais concentrados na porção mediana do plastídio.

Distribuição geográfica no Estado da Bahia - Em literatura: Município de Itanagra, Fazenda Socorro-Rio Sauípe (Bicudo \& Martins 1989: figura 21).

Ocorrência na área de estudo: BRASIL. BAHIA: Camaçari, APA Lagoas de Guarajuba (Estações 70, 87, 92, 94, 95); APA Rio Capivara (Estações 40, 41, 44, $53,56,63,64,77,78,81,83,84)$.

O primeiro registro de ocorrência da espécie no Brasil está em Nordstedt (1869), baseado em material coletado em Lagoa Santa, Estado de Minas Gerais, embora o autor tenha considerado o espécime identificado um pouco diferente do descrito originalmente por Ralfs (1848). 
Bicudo (1978) comentou que, por volta de 1910, os desmidiólogos passaram a usar o nome de $M$. radiata Hassall em detrimento de M. furcata C. Agardh ex Ralfs, que foi totalmente abandonado. Tal uso deveu-se à dificuldade de entender o que realmente seria $M$. furcata, uma prática errônea porque Ralfs (1848), o ponto oficial de partida para os estudos nomenclaturais em Desmidiaceae, colocou M. radiata Hassall na sinonímia de $M$. furcata. O nome que prevalece para esta espécie é, obrigatoriamente, M. furcata.

As populações observadas foram constituídas por grandes números de indivíduos, o que permitiu observar uma boa extensão do polimorfismo entre seus exemplares. $\mathrm{O}$ acentuado polimorfismo detectado tornou difícil considerar os organismos pertencentes a um mesmo táxon. A variação morfológica ocorreu, principalmente, nas incisões interlobares e interlobulares, que ora se apresentaram mais rasas, com a parte basal do lobo polar mais larga e a dos lobos polares mais curtas, levando-nos a confundi-los com representantes de $M$. furcata $\mathrm{C}$. Agardh ex Ralfs var. pseudocrux (Grönblad) C. E. M. Bicudo \& Sormus; outras vezes apresentavam incisões interlobulares e interlobares mais profundas, com o lobo polar relativamente mais estreito, de margem apical convexa e lóbulos mais delgados, típico de $M$. furcata var. furcata. Ademais, a variação observada nas atuais populações mostrou inúmeras expressões morfológicas intermediárias, que estabeleceram, no conjunto, um contínuo morfológico razoável.

Segundo Bicudo \& Sormus (1982), é melhor considerar M. furcata var. furcata e M. furcata var. pseudocrux sinônimos heterotípicos (taxonômicos), já que ambas são bastante polimórficas e por ser difícil reconhecer a variação inter-específca e/ou intravarietal numa população natural. Seguimos tal proposta ao considerar todos os indivíduos atualmente estudados como M. furcata var. furcata.

Os exemplares que analisamos concordaram com a descrição, as medidas e as ilustrações dos espécimes em Krieger (1939) para espécimes da Europa, Thomasson (1963), para espécimes do Chile (como M. radians W. B. Turner), Prescott et al. (1977), para espécimes da América do Norte e em Bicudo \& Sormus (1982), para espécimes do Estado de São Paulo, porém, diferem de todos eles por apresentarem medidas celulares pouco maiores.

Micrasterias laticeps Nordst. var. laticeps Vidensk. Meddr. danske naturh. Foren. 1869(14-15):220, pl. 2, fig. 14. 1869. Figura 12
Célula 1,2-1,4 vezes mais larga que longa, 112,5$115 \mu \mathrm{m}$ compr., 141-152 $\mu \mathrm{m}$ larg., lobo polar 117,5-130 $\mu \mathrm{m}$ larg., istmo 26-27,5 $\mu \mathrm{m}$ larg., contorno quadrangular, profundamente constrita na parte média, seno mediano fechado, abrindo para as extremidades em ângulo agudo; semicélulas 3-lobadas, lobo polar fusiforme a levemente subcuneiforme, margem superior convexa, raras vezes ligeiramente retusa no meio, ângulos acuminados, 1 espinho terminal disposto horizontalmente, voltado para cima ou para baixo, lobos basais semifusiformes, dispostos horizontalmente, 2-denticulados nas extremidades, incisão interlobar profunda, acutangular; parede celular finamente pontuada; vista vertical fusiforme; cloroplastídio axial, 1 prega ao longo do lobo polar, pirenóides vários, esparsos.

Distribuição geográfica no Estado da Bahia - Em literatura: Bahia, local não especificado $\left(13^{\circ} \mathrm{S}, 38^{\circ} \mathrm{W}\right)$ (Förster 1964: pl. 14, figura 7, pl. 45, figura 7). Município de Itanagra, fazenda Boneco, riacho Iboaçu (Bicudo \& Martins 1989: figura 32).

Ocorrência na área de estudo: BRASIL. BAHIA: Camaçari, APA Lagoas de Guarajuba (Estação 95); APA Rio Capivara (Estações 49, 52, 62).

A espécie em pauta foi proposta por Nordstedt (1869) a partir de material coletado em Lagoa Santa, Estado de Minas Gerais. Baseado nas dimensões celulares e na atenuação dos lobos basais, o referido autor considerou M. laticeps Nordst. dividida em duas formas: major e minor. A ilustração da f. major só foi publicada em Nordstedt (1877: pl. 2, fig. 14) e a f. minor jamais foi ilustrada pelo autor.

Krieger (1939) reconheceu seis variedades taxonômicas de M. laticeps Nordst., além da típica, sendo uma delas a var. minor calcada na f. minor em Nordstedt (1869).

Bicudo \& Senna (1975) concluíram que, através da análise de uma população da espécie, que sua variedade típica e a var. minor deveriam ser consideradas sinônimos do ponto de vista nomenclatural, uma vez que as diferenças de tamanho e grau de atenuação dos lobos desapareceram na análise da população e não podem, por isso, ser considerados critérios adequados para a delimitação das duas variedades taxonômicas.

Bicudo \& Sormus (1972), fizeram um estudo sobre o polimorfismo em $M$. laticeps Nordst. e observaram grande variação morfológica quanto ao número de dentículos que encimam os lobos polares e basais das semicélulas e ao desenvolvimento dos lobos basais até sua total ablação. Embora tenhamos examinado um número razoável de indivíduos, não registramos qualquer 
das expressões polimórficas ilustradas por Bicudo \& Sormus (1972).

As populações analisadas concordaram perfeitamente com as descrições e ilustrações de M. laticeps var. laticeps em Krieger (1939), para material da Europa, Förster (1964: 379, pl. 14, fig. 5, pl. 45, fig. 6, como $M$. laticeps Nordst. var. laticeps f. depressa H. Krieg. \& A. M. Scott), para material do Estado da Bahia e de Conceição, no Estado de Goiás, Prescott et al. (1977), para material dos Estados Unidos da América e Canadá, Bicudo \& Sormus $(1972,1982)$, para material do Estado de São Paulo e em Bicudo \& Martins (1989), para material do Estado da Bahia.

Micrasterias laticeps Nordst. var. acuminata H. Krieg. In Rabenhorst, Kryptogamen-Fl. Deutschl. 13(2):14, pl. 98, fig. 2. 1939.

Figura 13

Célula 1,2-1,4 vezes mais larga que longa, 88-91,5 $\mu \mathrm{m}$ compr., 115-119 $\mu \mathrm{m}$ larg., lobo polar 102,5-107,5 $\mu \mathrm{m}$ larg., istmo 17-20 $\mu \mathrm{m}$ larg., contorno aproximadamente circular, profundamente constrita na parte média, seno mediano fechado, abrindo para as extremidades em ângulo agudo; semicélulas 3-lobadas, lobo polar fusiforme, levemente subcuneiforme, margem superior convexa, raro ligeiramente retusa no meio, ângulos acuminados, 1 espinho terminal, disposto horizontalmente, lobos basais semifusiformes, dispostos horizontalmente, 1 espinho curto nas extremidades, levemente arredondado; incisão interlobar profunda, acutangular; parede celular finamente pontuada; vista vertical fusiforme; vista lateral fusiforme, cloroplastídio e pirenóide não observados.

Distribuição geográfica no Estado da Bahia - Primeira citação de ocorrência da espécie para o Estado.

Ocorrência na área de estudo: BRASIL. BAHIA: Camaçari, APA Lagoas de Guarajuba (Estação 7); APA Rio Capivara (Estação 76).

Micrasterias laticeps Nordst. var. acuminata $\mathrm{H}$. Krieg. difere da variedade típica da espécie por apresentar as extremidades dos lobos basais acuminadas.

Krieger (1939) propôs a var. acuminata baseado em material em Borge (1903), coletado em Corumbá, Estado de Mato Grosso do Sul, por apresentar todos os lobos acuminados.

A variação morfológica encontrada nas atuais populações estudadas está de acordo com a citada em literatura, isto é, refere-se às margens apicais dos lobos apicais que ora se apresentaram levemente retusas na parte média ora uniformemente convexas e às incisões interlobares que ora apresentaram os vértices acuminados ora levemente arredondados.

O material ora analisado concorda, plenamente, com as ilustrações e descrições em Krieger (1939) a partir de material do Estado de Mato Grosso do Sul, Förster (1964), do Estado de Goiás, Bicudo \& Sormus (1982), do Estado de São Paulo e em Lopes \& Bicudo (2003), da Amazônia.

Micrasterias mahabuleshwarensis J. Hobson var. ampullacea (W. M. Maskell) Nordst. K. Svenska VetenskAkad Handl. 4, 2(8):30, pl. 2, fig. 8. $1888 \equiv$ Micrasterias ampullacea W. M. Maskell, Proc. N. Zeal. Inst. 13:304, pl. 11, fig. 6-8. 1881.

Figura 14

Célula $c a$. 1,2 vezes mais longa que larga, 138148,5 $\mu \mathrm{m}$ compr., $110-120 \mu \mathrm{m}$ larg., lobo polar 68-77 $\mu \mathrm{m}$ larg., istmo 20-24,5 um larg., contorno elíptico, constrição mediana profunda, seno mediano retilíneo; semicélula 5-lobada, incisões laterais cilíndricas na parte basal, abrindo na parte distal, margens côncavas, ápice côncavo, 2 pares de grânulos intramarginais no meio, ângulos amplamente projetados lateralmente, 3-4-denticulados, margens serrilhadas, 1 par de processos acessórios, assimétricos, divergentes, truncados, quase retos, na base dos ângulos, incisão pouco profunda entre os lobos laterais e basais, lobos cônico-truncados, margens 3-4-denticuladas no ápice, parede celular hialina, grânulos intramarginais formando 1 série mais ou menos regular ao longo das incisões interlobares e istmial, face da semicélula com 1 intumescência logo acima do istmo, ornamentada por 1 conjunto de grânulos; vistas apical e lateral fusiformerombóides, cloroplastídio seguindo o contorno da célula; pirenóides não observados.

Distribuição geográfica no Estado da Bahia - Primeira citação de ocorrência da espécie para o Estado.

Ocorrência na área de estudo: BRASIL. BAHIA: Camaçari, APA Rio Capivara (Estações 10, 12, 15, 40, 41, 42, 77, 85).

A var. ampullacea difere da típica da espécie por apresentar contorno celular completamente serrilhado e lóbulos laterais e basais inflados, com os vértices arredondados. Grönblad (1945) registrou pioneiramente a ocorrência dessa variedade var. ampullacea em território brasileiro baseado em material do Estado do Pará, porém, não incluiu descrição nem ilustração do material que examinou.

Os espécimes estudados estão de acordo com as descrições e ilustrações apresentadas por Förster (1969) 
e Thomasson (1971), para material da Amazônia, Krieger (1939), para material da Europa, Prescott et al. (1977), para material da América do Norte, e Croasdale \& Flint (1986), para material da Nova Zelândia.

Micrasterias mahabuleshwarensis J. Hobson var. mahabuleshwarensis f. mahabuleshwarensis Quart. Jour. Microsc. Sci. 1863:169, fig. p.168. 1863.

Figura 15

Célula 1,2-1,6 vezes mais longa que larga, 170$200 \mu \mathrm{m}$ compr., 145-152,5 $\mu \mathrm{m}$ larg., lobo polar 86-97 $\mu \mathrm{m}$ larg., istmo 27,5-32 $\mu \mathrm{m}$ larg., contorno semielíptico, constrição mediana profunda, seno mediano acutangular, profundo; semicélula 5-lobada, lobo apical cilíndrico na parte basal, abrindo decididamente na parte distal, margens côncavas, ápice côncavo, 1-2 pares de grânulos intramarginais no meio, ângulos amplamente projetados lateralmente, 3-4 dentículos, margens serrilhadas, 1 par de processos acessórios, assimétricos, divergentes, truncados, quase retos, na base dos ângulos, incisões interlobares moderadamente profundas, amplamente abertas, lobos laterais e basais serrilhados, lisos próximo à base, cônico-truncados, extremidade 3-4-denticuladas
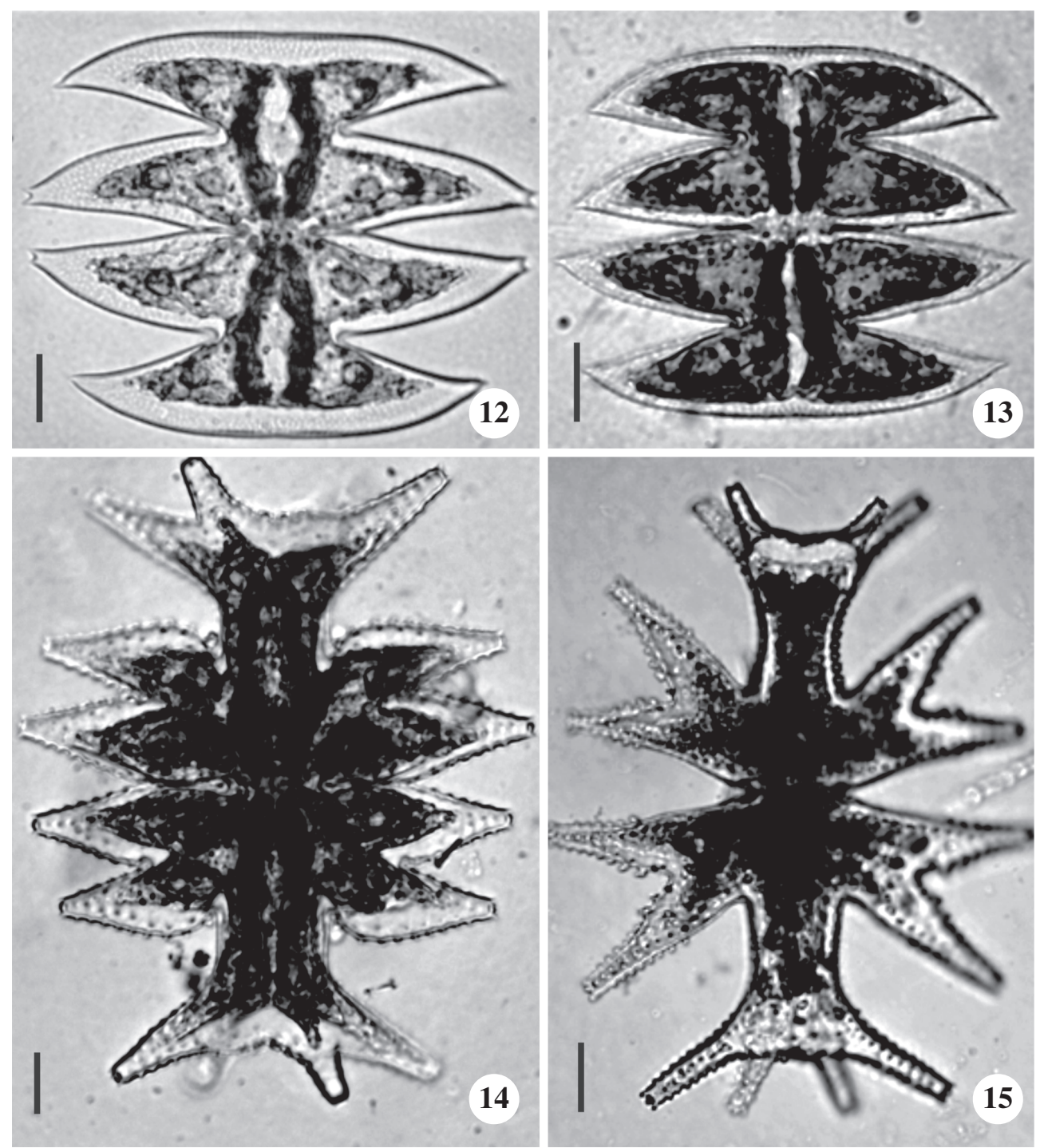

Figuras 12-15. 12. Micrasterias laticeps var. laticeps. 13. M. laticeps var. acuminata H.Krieg. 14. M. mahabuleshwarensis var. ampullacea. 15. M. mahabuleshwarensis var. mahabuleshwarensis f. mahabuleshwarensis. $($ Barra $=20 \mu \mathrm{m})$

Figures 12-15. 12. Micrasterias laticeps var. laticeps. 13. M. laticeps. var. acuminata.. 14. M. mahabuleshwarensis var. ampullacea. 15. M. mahabuleshwarensis var. mahabuleshwarensis f. mahabuleshwarensis. $(\mathrm{Bar}=20 \mu \mathrm{m})$ 
no ápice, tamanhos levemente desiguais entre si, indivisos; parede celular hialina, grânulos intramarginais formando 1 série mais ou menos regular ao longo das incisões interlobares e istmial; vistas apical e lateral não observadas; cloroplastídio seguindo o contorno da célula; pirenóides vários, esparsos.

Distribuição geográfica no Estado da Bahia - Primeira citação de ocorrência da espécie para o Estado.

Ocorrência na área de estudo: BRASIL. BAHIA: Camaçari, APA Lagoas de Guarajuba (Estações 10, 75, 89); APA Rio Capivara (Estações 76, 78, 80).

Borge $(1899,1903)$ citou, pela primeira vez, a ocorrência da espécie nos estados do norte do Brasil, contudo, não descreveu nem ilustrou o material que identificou. Grönblad (1945) ilustrou um espécime de M. mahabuleshwarensis var. mahabuleshwarensis $\mathrm{f}$. mahabuleshwarensis, entretanto, não acrescentou qualquer comentário a respeito do material que examinou.

Todos os exemplares que tivemos oportunidade de examinar não mostraram a decoração facial supraistmial constituída de grânulos, além de não termos observado a presença de dois espinhos maiores na base da incisão entre os lobos lateral e apical, de cada lado, a qual aparece claramente ilustrada em Prescott et al. (1977: pl. 143, fig. 1-2).

O material estudado está de pleno acordo com o descrito e ilustrado por West \& West (1905), a partir de material da Inglaterra, Prescott et al. (1977), de material da América do Norte e por Croasdale \& Flint (1986), de material da Nova Zelândia.

Micrasterias pinnatifida (Kütz.) Ralfs var. pinnatifida f. pinnatifida Brit. Desmidieae 77, pl. 10, fig. 3. $1848 \equiv$ Euastrum pinnatifidum Kütz., Phycol. Germ. 134. 1845. Figura 16

Célula $c a$. 1,2 vezes mais larga que longa, 62,567,5 $\mu \mathrm{m}$ compr., 68,5-71,5 $\mu \mathrm{m}$ larg., lobo polar 40-42,5 $\mu \mathrm{m}$ larg., istmo 12-14,5 $\mu \mathrm{m}$ larg., contorno subquadrático, constrição mediana profunda, seno mediano fechado, linear próximo do istmo, abrindo em ângulo agudo para as extremidades; semicélulas 3-lobadas, incisões acutangulares, abertas, lobo polar subcuneiforme a quase reto, disposto horizontalmente, margem superior convexa, ligeiramente retusa no meio, extremidades agudas, 2-denticuladas, espinhos curtos, superiores geralmente voltados para cima, inferiores retos ou voltados para baixo, lobos basais semifusiformes, dispostos horizontalmente, extremidades 2-denticuladas, incisão interlobar acutangular, vértice arredondado; parede celular hialina, finamente pontuada; vista apical fusiforme; vista lateral subelíptica; cloroplastídio seguindo a forma da semicélula, 2 pregas verticais ao longo das margens laterais do lobo polar, pirenóides 8-12.

Distribuição geográfica no Estado da Bahia - Em literatura: Município de Itanagra, Fazenda Socorro-Rio Sauípe (Bicudo \& Martins, 1989: figura 38).

Ocorrência na área de estudo: BRASIL. BAHIA: Camaçari, APA Lagoas de Guarajuba (Estações 1, 3, 5, 7 , 8, 57, 70, 71, 88, 89, 93, 94, 95); APA Rio Capivara (Estações $11,13,14,15,16,32,33,34,35,36,38,48,49,51,52,53$, $54,61,62,63,64,65,66,67,77,78,79,80,81,82,83)$.

De acordo com a literatura, M. pinnatifida (Kütz.) Ralfs é uma espécie bastante polimórfica e, segundo Bicudo \& Sormus (1974), diversas variedades taxonômicas nela classificadas podem ser apenas expressões morfológicas da variedade-tipo. Polimorfismo de tal extensão não foi registrado nas populações estudas. A variação observada foi de pequena monta, pouco expressiva e apresentou-se apenas na margem apical das semicélulas, que às vezes foi reta.

Krieger (1939), mostrou-se indeciso ao inventariar as Micrasterias da Europa Central no que tange à posição sistemática de algumas variedades de $M$. pinnatifida, supondo que algumas dessas variedades nada mais seriam que formas teratológicas ou formas morfologicamente reduzidas da variedade típica da espécie. Prescott \& Scott (1942), sugeriram que o grande polimorfismo de M. pinnatifida seria devido à grande sensibilidade desses organismos às mudanças das condições físicas e químicas do ambiente.

Bicudo \& Sormus (1982), sugeriram a necessidade urgente da realização de estudos populacionais para confirmar ou refutar a validade das variedades da espécie, com o que concordamos plenamente.

As populações analisadas durante este estudo concordaram com as descrições e ilustrações em Förster (1969), preparadas de material da Amazônia, Bicudo \& Sormus $(1974,1982)$, de material do Estado de São Paulo, Croasdale \& Flint (1986), de material da Nova Zelândia e Brook \& John (2002), de material das Ilhas Britânicas.

Micrasterias radiosa Ralfs var. elegantior (G. S. West) Croasdale In Prescott et al. Syn. N. Amer. Desm. 2(2): 181, pl. 132, fig. 2-4. $1977 \equiv$ Micrasterias sol (Ehrenb.) Kütz. var. ornata Nordst. f. elegantior G. S. West, Mém. Soc. Neuchatel. Sci. Nat. 5:1035, pl. 22, fig. 44. 1914. Figura 17

Célula 1-1,1 vezes mais longa que larga, $150-172 \mu \mathrm{m}$ compr., 148-166,5 $\mu \mathrm{m}$ larg., lobo polar 30-38,5 $\mu \mathrm{m}$ larg., istmo 18,5-24 $\mu \mathrm{m}$ larg., contorno circular, constrição 
mediana profunda, seno mediano linear, fechado próximo do istmo, levemente aberto para a extremidade; semicélula 5-lobada, incisões interlobares profundas, lineares, semiabertas, lobos laterais e basais cuneados, levemente desiguais entre si, laterais pouco maiores, ambos subdivididos por 7 incisões acutangulares resultando em 8 partes iguais, 2-denticuladas, lobo apical subcilíndrico, margens retilíneas, subparalelas entre si, ápice chanfrado no meio, 1 elevação de cada lado com 1 dentículo, ângulos emarginados, 2-3-denticulados, parede celular hialina, lisa; vista apical fusiforme, 1 leve intumescência na região mediana da célula; vista lateral não observada; cloroplastídio seguindo o contorno da célula; pirenóides vários, esparsos.

Distribuição geográfica no Estado da Bahia - Primeira citação de ocorrência da espécie para o Estado.

Ocorrência na área de estudo: BRASIL. BAHIA: Camaçari, APA Lagoas de Guarajuba (Estações 1, 2, 7 , 8, 24, 96); APA Rio Capivara (Estações 10, 11, 14, 16, $33,51,52,53,54,55,64,65,67,68,79,84,85)$.

A presente variedade difere da típica da espécie por possuir lobos de qualquer ordem fitáceos, com incisões dos lobos polares e laterais estreitas, profundas, abertas e com a parte central da semicélula inteira extremamente reduzida.

Segundo Prescott et al. (1977), M. radiosa var. elegantior pode ou não ter diminutos espinhos ao longo das incisões maiores e alertaram para o fato de que a espécie pode ser confundida com $M$. radiosa Ralfs var. ornata Nordst., que sempre apresenta uma fileira de espinhos ao longo de todas as incisões ou, pelo menos, das incisões mais profundas.

Grönblad (1945) foi o primeiro a registrar a presença da espécie no Brasil, após examinar material coletado no rio Ayayá, Estado do Pará e identificado com $M$. radiosa Ralfs var. ornata Nordst. f. elegantior G. S. West. Nesse trabalho, o autor comentou não ter encontrado transição entre as forma típica da espécie e a forma elegantior.

Bicudo \& Sormus (1982), mencionaram, ao estudarem M. radiosa var. ornata f. elegantior do Estado de São Paulo, que foram analisadas amostras com indivíduos com espinhos ao longo das incisões interlobares e do seno mediano além de outros poucos espalhados na porção mediana da célula, bem como amostras com organismos completamente glabros.

O material analisado concorda com as descrições, ilustrações e medidas apresentadas por Bicudo \& Sormus (1982), para material do Estado de São Paulo, Grönblad (1945), para material do Estado do Pará, Prescott et al.
(1977), para material da América do Norte e Thomasson (1959), para a Argentina.

Micrasterias rotata (Grev.) Ralfs ex Ralfs var. rotata Annals Mag. Nat. Hist. 14:259, pl. 6, fig. 1. 1844. Figura 18

Célula 1,1-1,2 vezes mais longa que larga, (275-) 350-356 $\mu \mathrm{m}$ compr., (208-)250-316 $\mu \mathrm{m}$ larg., lobo apical (55-)74-86 $\mu \mathrm{m}$ larg., (28-)48-50 $\mu \mathrm{m}$ larg., contorno subcircular, profundamente constrita na região mediana, seno mediano linear em todo comprimento; semicélulas 5-lobadas, incisões lineares, lobo polar gradualmente dilatado para o ápice, em geral pouco projetado além dos lobos laterais, lados levemente côncavos, ápice retusochanfrado, ângulos levemente prolongados, 2-denticulados, lobos laterais e basais desiguais entre si, amplamente cuneiformes, cada qual dividido em 2 lobos por 1 incisão mais profunda, lobos laterais maiores que os basais, subdivididos em 4 partes iguais, chanfradas ou 2-denticuladas, por meio de 3 incisões apertadamente lineares e a última aberta, acutangular, lobos basais, geralmente divididos em 2 pares, chanfrados; parede celular hialina, delicadamente pontuada; vista apical aproximadamente fusiforme, pólos acuminados, 1 intumescência suave no meio da cada semicélula; vista lateral não observada; cloroplastídio seguindo o contorno da célula, 2 pregas ao longo das margens do lobo polar e 1 ao longo do seno mediano; pirenóides vários, esparsos.

Distribuição geográfica no Estado da Bahia - Primeira citação de ocorrência da espécie.

Ocorrência na área de estudo: BRASIL. BAHIA: Camaçari, APA Rio Capivara (Estações 37, 44, 45, 46, $50,78)$.

O primeiro registro da ocorrência da espécie no Brasil consta em Nordstedt (1869), baseado em uma amostra coletada próximo a Lagoa Santa, Estado de Minas Gerais. O referido autor, contudo, não ilustrou o espécime que identificou.

O material atualmente examinado concorda com a descrição, as medidas e as ilustrações em Bicudo \& Sormus (1982), as quais foram feitas a partir de material coletado no Estado de São Paulo e em Brook \& John (2002), a partir de material das Ilhas Britânicas. Contudo, apresentou medidas celulares pouco maiores que as referidas por Lopes \& Bicudo (2003), para material da Amazônia e por Sormus (1991) para material do Estado de São Paulo.

Bicudo \& Sormus (1982) documentaram o grande polimorfismo que a espécie apresenta, principalmente, quanto 1) à forma da porção distal dos lóbulos polares, 2) ao grau de projeção dos lóbulos polares, 3) à subdivisão 
dos lóbulos basais e 4) à margem apical dos lóbulos de última ordem.

Durante o presente estudo, foram poucos os exemplares de $M$. rotata var. rotata que tivemos oportunidade de observar e, entre esses, não foi observada variação morfológica expressiva.

Micrasterias truncata (Corda) Bréb. ex Ralfs var. pusilla G. S. West Mém. Soc. Neuchât. Sci. Nat. 2, 5:1035, pl. 22, fig. 42-43. 1914.

Figura 19

Célula 1-1,1 vezes mais larga que longa, 53,5-56 $\mu \mathrm{m}$ compr., 58,5-60 $\mu \mathrm{m}$ larg., lobo polar 40-45 $\mu \mathrm{m}$ larg., istmo 11-12,5 $\mu \mathrm{m}$ larg., contorno aproximadamente circular, constrição mediana profunda, seno mediano aberto, acutangular; semicélula sub-retangular em vista frontal, 5-lobada, incisões interlobares pouco profundas, abertas, lobos basais e laterais sub-retangulares, iguais entre si, 2-lobulados, incisões interlobulares, abertas, côncavas, lobos 2-denticulados, subfusiformes, ângulos acuminados, formando 1 pequeno dente, margem apical levemente côncava; parede celular hialina, finamente pontuada; vistas apical e lateral não observadas; cloroplastídio axial; pirenóides diversos, espalhados em cada plastídio.

Distribuição geográfica no Estado da Bahia - Primeira citação de ocorrência da espécie para o Estado.

Ocorrência na área de estudo: BRASIL. BAHIA: Camaçari, APA Lagoas de Guarajuba (Estações 5, 6, 7,
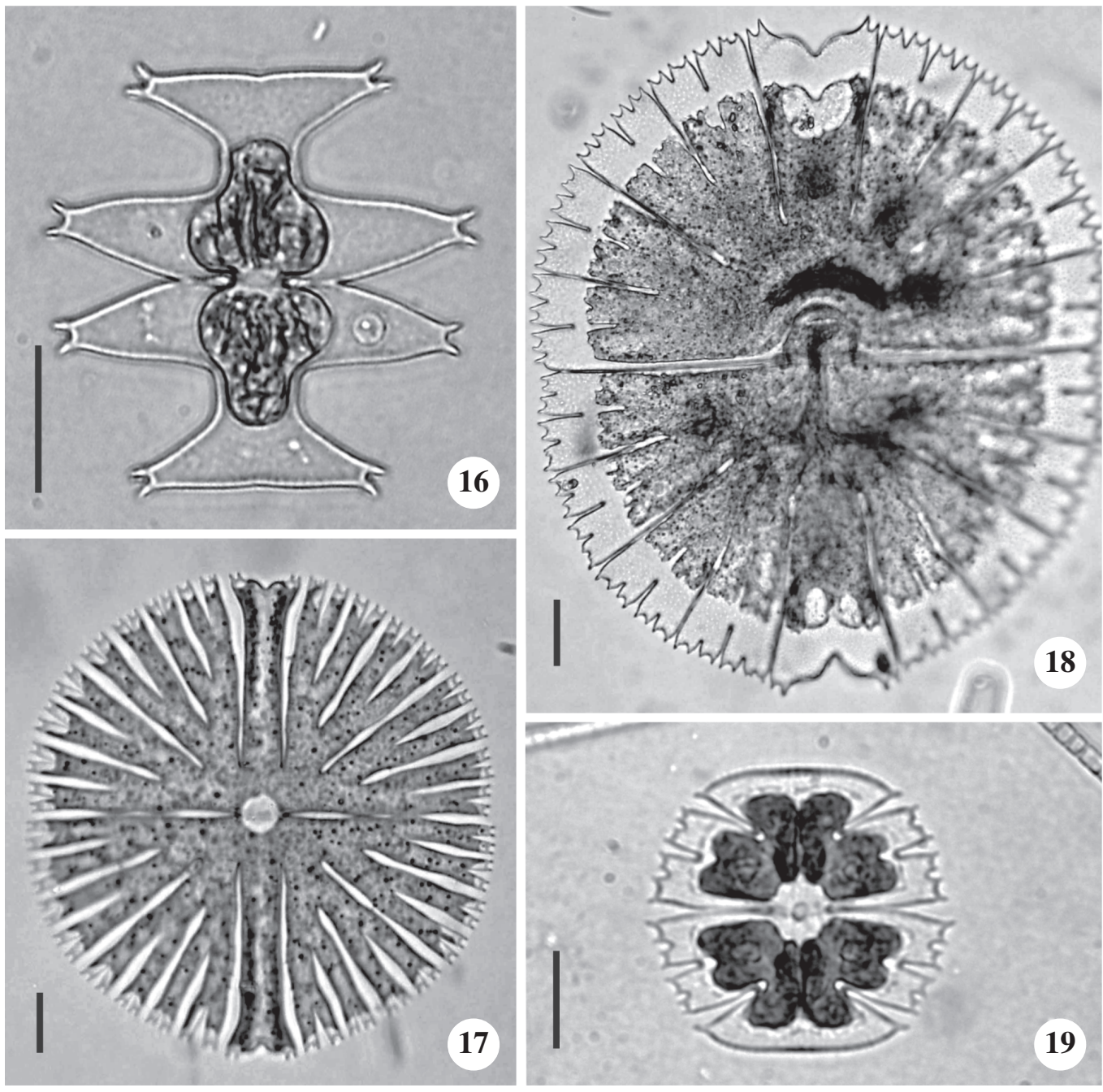

Figuras 16-19. 16. Micrasterias pinnatifida var. pinnatifida f. pinnatifida. 17. M. radiosa var. elegantior. 18. M. rotata var. rotata. 19. M. truncata var. pusilla. $($ Barra $=20 \mu \mathrm{m})$

Figures 16-19. 16. Micrasterias pinnatifida var. pinnatifida f. pinnatifida. 17. M. radiosa var. elegantior. 18. M. rotata var. rotata. 19. M. truncata. var. pusilla. $($ Bar $=20 \mu \mathrm{m})$ 
17, 18, 19, 22, 25, 26, 29, 72, 74, 90, 93, 94); APA Rio Capivara (Estações 32, 33, 34, 35, 36).

Micrasterias truncata var. pusilla difere da variedade típica da espécie por apresentar células de contorno subcircular, mais largas que longas e incisões comparativamente mais profundas e angulares entre os lobos laterais e basais, além dos ângulos dos lobos polares serem acuminados e de tamanho relativamente reduzido.

Borge (1918), foi o primeiro a registrar a existência da var. pusilla no Brasil, fazendo-o a partir de amostras coletadas no Estado de São Paulo e identificadas como "forma minor". Krieger (1939) considerou esta forma dentro do espectro de variação da var. pusilla.

Bicudo \& Sormus (1982), diferiram essa variedade da típica da espécie pela primeira apresentar células de menor tamanho (a variedade-tipo possui o dobro do tamanho) além de suas células ligeiramente mais largas do que longas e os ângulos dos lobos polares não serem acuminados.

Micrasterias truncata var. pusilla apresenta grande variação morfológica, o que, às vezes, torna até bastante problemática a identificação taxonômica de seus representantes. Quando as expressões morfológicas ocorrem nas incisões interlobares, que se apresentam mais profundas podem ser confundidas com representantes de $M$. decemdentata (Nägeli) W. Archer, da qual a primeira difere por apresentar os lobos polares relativamente mais curtos; e de M. abrupta West \& G. S. West, da qual difere pela forma do lobo polar e pelo seno mediano linear e fechado. Prescott et al. (1977), são da opinião de que estes três táxons deveriam ser combinados em um único.

Os espécimes analisados estão de pleno acordo com a descrição e as ilustrações de Bicudo \& Sormus (1982) elaboradas de material do Estado de São Paulo, Lopes \& Bicudo (2003), de material da Amazônia e de Prescott et al. (1977), de material da América do Norte.

Conclusões - Foram identificados 14 táxons de Micrasterias, dos quais apenas M. laticeps var. laticeps, M. pinnatifida var. pinnatifida f. pinnatifida e $M$. furcata var. furcata $\mathrm{f}$. furcata já haviam sido registrados em trabalhos anteriores para o Estado da Bahia.

Micrasterias americana var. bahiensis I. B. Oliveira, C. E. M. Bicudo \& C. W. N. Moura é descrita como uma novidade para a ciência, a partir de amostra populacional coletada na APA Lagoas de Guarajuba (HUEFS 125619).

Os 10 táxons seguintes são adições à desmidioflórula da Bahia: M. alata, M. arcuata var. subpinnatifida f. subpinnatifida, M. borgei var. borgei,
M. foliacea var. foliacea, M. furcata var. furcata f. furcata, M. laticeps var. laticeps, M. laticeps var. acuminata, M. mahabuleshwarensis var. ampullacea, M. mahabuleshwarensis var. mahabuleshwarensis $\mathrm{f}$. mahabuleshwarensis, M. pinnatifida var. pinnatifida f. pinnatifida, $M$. radiosa var. elegantior $M$. rotata var. rotata e $M$. truncata var. pusilla.

Micrasterias mahabuleshwarensis var. ampullacea e $M$. rotata var. rotata foram registradas apenas na APA Rio Capivara.

Micrasterias pinnatifida var. pinnatifida $\mathrm{f}$. pinnatifida e $M$. alata foram as espécies de ocorrência mais freqüente durante o atual estudo, por estarem presentes em $38,6 \%$ e $36,6 \%$, respectivamente, das amostras analisadas.

Agradecimentos - ACapes, Coordenação de Aperfeiçoamento de Pessoal do Ensino Superior, pela concessão da Bolsa de Mestrado à primeira autora; à Universidade Estadual de Feira de Santana e ao Instituto de Botânica da Secretaria do Meio Ambiente do Estado de São Paulo, pelo apoio logístico; ao Programa de Pós-Graduação em Botânica da UEFS, pelo auxílio financeiro concedido para a realização das coletas e aos assessores e editores pelas sugestões.

\section{Referências bibliográficas}

BICUDO, C.E.M. 1978. Micrasterias furcata or Micrasterias radiata, which one? Taxon, 27:298-299.

BICUDO, C.E.M. \& SENNA, P.A.C. 1975. Use of mensurementes for diferentiation of infraespecific taxa in Micrasterias laticeps. British Phycological Journal 10:43-47.

BICUDO, C.E.M. \& SORMUS, L. 1972. Polymorphism in the desmid Micrasterias laticeps and its taxonomical implications. Journal of Phycology 8:273-242.

BICUDO, C.E.M. \& SORMUS, L. 1974. Polymorphism in the desmid Micrasterias pinnatifida and its taxonomical implications. Journal of Phycology 10:274-279.

BICUDO, C.E.M. \& SORMUS, L. 1982. Desmidiofórula paulista, 2: gênero Micrasterias C. Agardh ex Ralfs. Bibliotheca Phycologica 57:1-230.

BICUDO, C.E.M. \& MARTINS, D.V. 1989. Desmídias (Zygnemaphyceae) de Itanagra, Estado da Bahia, Brasil. Revista Brasileira de Biologia 49:309-324.

BICUDO, C.E.M. \& MENEZES, M. 2006. Gêneros de algas de águas continentais do Brasil: chave para identificação e descrições. RiMa Editora, São Carlos.

BORGE, O. 1899. Süsswasser-Chlorophyceen. Kungliga Svenska Vetenskapsakademiens Handlingar: sér. B, 24(12):1-33.

BORGE, O. 1903. Die Algen der ersten Regnellschen Expedition, 2: Desmidiaceae. Arkiv för Botanik 1:71-138. 
BORGE, O. 1918. Die von Dr. A. Löfgren in São Paulo gessammelten Süsswasseralgen. Arkiv för Botanik 15(13):1-108.

BROOK, A.J. \& JOHN, D.M. 2002. Phyllum Chlorophyta (Green Algae) Ordem Zygnematales. In John, D.M., Whiton, B.A. \& Brook, A.J. (Eds.). The freshwater algal flora of the British Isles: an identification guide of freshwater and terrestrial algae. Cambridge University Press, Cambridge. p.410-593.

CROASDALE, H. \& FLINT, E.A. 1986. Flora of the New Zealand: freshwater algae, Chlorophyta, desmids, with comments on their habitats. DSIR Botany Division, Christchurch. v.1.

FÖRSTER, K. 1963. Desmidiaceen aus Brasilien, 1: NordBrasilien. Revue Algologique 7:38-92.

FÖRSTER, K. 1964. Desmidiaceen aus Brasilien, 2, Teil: Bahia, Goyaz, Piauhy und Nord-Brasilien. Hydrobiologia 22:321-505.

FÖRSTER, K. 1969. Amazonische desmidien, 1. Amazoniana 2:5-116.

FÖRSTER, K. 1974. Amazonische desmidien, 2. Amazoniana 2:135-242.

GRÖNBLAD, R. 1945. De algis brasiliensibus praecipue Desmidiaceis in regione inferiore fluminis Amazonas. Acta Societatis Scientiarum Fennicae: nov. sér. B, 2:1-43.

KRIEGER, W. 1939. Die Desmidiacen. In KryptogamenFlora von Deutschland, Österreich und der Schweiz. (L. Rabenhorst, ed.) Akademische Verlasgsgesellschaft m.b.h., Leipzig. 13(2):1-117.

LOPES, M.R.M. 1992. Desmidioflórula do Lago Andirá (rio Sere), Estado do Amazonas. Dissertação de mestrado em Ciências Biológicas - Botânica, Universidade de São Paulo, SP.

LOPES, M.R.M. \& BICUDO, C.E.M. 2003. Desmidioflórula de um lago da planície de inundação do Rio Acre, Estado do Amazonas, Brasil. Acta Amazônica 33:167-212.

MARTINS, D.V. \& BICUDO, C.E.M. 1987. Desmídias da Ilha de Itanharé, Estado da Bahia, Brasil. Revista Brasileira de Biologia 47:1-16.
NORDSTEDT, C.F.O. 1869. Symbolae ad floram Brasiliae centrals congnoscedam. Öfversigt af Kungliga Vetenskapsakademiens förhandlingar 1869(14-15): 195-234.

NORDSTEDT, O. 1877. Nonnullae algae aquae dulcis brasilienses. Videnskabelige Meddelelser fra den Naturhistoriske Forening i Kjöbenhavn 3:15-29.

PRESCOTT, G.W. \& SCOTT, A.M. 1942. The fresh-water algae of the southern United States, 1: desmids from Mississippi, with descriptions of new species and varieties. Transactions of the American Microscopical Society 61:1-29.

PRESCOTT, G.W., CROASDALE, H.T. \& VINYARD, W.C. 1977. A synopsis of North American desmids, 2(2): Desmidiaceae: Placodermae sect. 2. University of Nebraska Press, Lincoln.

RALFS, J. 1848. The British Desmidieae. Reeve, Benham \& Reeve, London.

SOPHIA, M.G. 1989. Contribuição ao conhecimento do gênero Micrasterias C.Agardh ex Ralfs (Zygnemaphyceae) do Estado do Rio de Janeiro. Hoehnea 16:63-87.

SORMUS, L. 1980. Revisão dos grupos de espécies arcuata e laticeps do gênero Micrasterias (Zygnemaphyceae). Tese de doutorado, Universidade de São Paulo, São Paulo.

SORMUS, L. 1991. Desmidiaceae (Zygnemaphyceae) da Serra do Cipó, Estado de Minas Gerais, Brasil, 1: gênero Micrasterias C. Agardh ex Ralfs. Hoehnea 18(2):1-29.

THOMASSON, K. 1959. Nahuel Huapi: plankton of some lakes in an Argentine National Park, whith notes on terrestrial vegetation. Acta Phytogeographica Suecica 42:1-83.

THOMASSON, K. 1963. Araucanian Lakes: plankton studies in North Patagonia with notes on terrestrial vegetation. Acta Phytogeographica Suecica 47:1-139.

THOMASSON, K. 1971. Amazonian desmids. Mémoires Institute Royal des Sciences Naturelles de Belgique, ser. 2, 86:1-57.

WEST, W. \& WEST, G.S. 1905. A monograph of the British Desmidiaceae. Vol. 2. The Ray Society, London. 